\title{
A two-stage stochastic supply chain scheduling problem with production in cellular manufacturing environment: A case study
}

\author{
Bahman Esmailnezhad $^{1}$, Mohammad Saidi-mehrabad ${ }^{2 *}$ \\ ${ }^{1}$ PhD Candidate, Department of Industrial Engineering, Iran University of Science and Technology, \\ University Ave. Narmak, Tehran, P.O. Box 1684613114, Iran \\ E-mail Address: b_esmailnezhad@ ind.iust.ac.ir \\ Phone Number: +989144633216 \\ ${ }^{2}$ Professor, Department of Industrial Engineering, Iran University of Science and Technology, \\ University Ave. Narmak, Tehran, P.O. Box 1684613114, Iran \\ E-mail Address: mehrabad@iust.ac.ir \\ Phone Number: $+98(21) 73225025$ \\ Abstract
}

An integrated decision in supply chain is a significant principle in order to compete in today's market. This paper proposes a novel mathematical model in a two-stage supply chain scheduling to cooperate procurement and manufacturing activities. The supply chain scheduling along with the production approach of cellular manufacturing under demand, processing time, and transportation time uncertainties makes business environment sustainably responsive to the changing needs of customers. Uncertainties are formulated by queuing theory. In this paper, a new mixed-integer nonlinear programming formulation is used to determine types of vehicles to carry raw materials, suppliers to procure, priority of each part in order to process, and cell formation to configure work centers. The goal is to minimize total tardiness. A linearization method is used to ease tractability of the model. A genetic algorithm is developed due to the NP-hard nature of the problem. The parameters of the genetic algorithm are set and estimated by Taguchi's experimental design. Numerous test problems are employed to validate the effectiveness of the modeling and the efficiency of solution approaches. Finally, a real case study and a sensitivity analysis are discussed to provide significant managerial insights and assess the applicability of the proposed model.

Keywords: mathematical optimization, supply chain scheduling, cellular manufacturing, queuing theory, meta-heuristic

\section{Introduction}

Nowadays, the intensifying pressure of competition in the market has forced manufacturers in order to pay attention to all steps from raw materials to finished products. Managing the material flow from supplier to customer as a unified system rather than a sequence of independent actions is the fundamental philosophy behind the supply chain management [1]. The purpose is connecting procurement activities, distribution network, and marketplace to manufacturing process in terms of making a unified decision. Therefore, customers are serviced at upper level and lower cost and manufacturers are getting competitive advantage through both cost reduction and product augmentation ([2] and [3]). Supply chain scheduling is looking for coordination between different parts of a supply chain. The collaboration of procurement, production, and transportation plays a key role in the supply chain scheduling. Therefore, supply chain scheduling is essential to improve efficiency and effectiveness of a supply chain. In practical terms, it is significant in industries such as automobile, electronics, and aviation owing to the fact that the production activities of these industries are decentralized [4]. This field is becoming more popular due to energy saving and reduction of fuel consumption [5]. In general, the collaboration of suppliers, shipping fleets, and manufacturer leads to customer satisfaction and it is achievable through selecting right supplier and shipping fleet to cooperate along with choosing a rational production approach. 
Raw materials provide from one or more suppliers, so manufacturers require to decide which supplier should be chosen. Consequently, one of the significant component of the supply chain scheduling is choosing the right supplier. Since raw material costs comprise a main part amongst the costs of finished products. So, it is important factor to gain market share amongst competitors. It can be easily found at a glance in the related literature that supplier selection has gotten visible attention by researchers ([6], [7], [8], [9], [10], and [11]). Thus, supplier selection takes into account as one of the most important measures for manufacturers in order to preserve a strategically competitive position. It leads to procure the right quantity of raw materials in the right quality at the right time and sensible cost.

The other important component of the supply chain scheduling is selecting the right manufacturing approach. The right manufacturing approach will help to be reactive to customer's changing requests and tackle the customers' challenges looking for high-quality, low-cost products. Furthermore, it will cope with fluctuating demands via the fair speed of adaptation and sufficient production of goods. Group technology has been experienced all over the world as a manufacturing system philosophy owing to its flexibility and adaptability [12]. Cellular manufacturing (CM) is the usage of the group technology concepts to shop floor layout design and firm reconfiguration. The $\mathrm{CM}$ provides flexibility for producing new products while affecting on declining production lead-time ([13] and [14]). Manufacturers have changed their traditional configuration like job shop and flow shop to new one such as the CM. the CM utilizes the positive features of job shop that is flexibility and variety, and flow shop which is efficiency and production volume, simultaneously ([15] and [16]). Also, the CM does not enforce manufacturers to necessarily invest in capital assets like flexible manufacturing systems (FMS) in order to achieve flexibility. The CM includes processing a group of similar parts on a devoted collection of machines or manufacturing processes [17]. The usage of the CM leads to numerous important benefits, which decreases not only material handling cost, set-up times, work-in-process inventory, and throughput times, but it also improves quality and simplifies scheduling ([18] and [19]). A successful design of the CM should be taken into account cell formation and cell management. Cell formation (CF) as a component of the $\mathrm{CM}$ contains the process of grouping the parts with similar processing necessities or design characteristics into part families and assigning machines into machine cells [20]. Each part family should produce totally in a machine cell. Nevertheless, parts may be manufactured in more than one cell in reality. Cell management relates to planning subjects such as scheduling and sequencing of operations. The scheduling considers the scheduling of each part within each cell [21] and the sequencing concerns the order of operations behind each machine [22].

Manufacturers have to turn their attention on uncertainties to enhance the sustainability of their business in today's competitive market. Uncertainty management will allow manufacturers to escalate their performance efficiently and effectively [23]. They must pay attention to uncertainties in whole of the their supply chain such as uncertain demand, the transfer time of shipping fleet, the delivery lead-time of suppliers, material handling time, and operation time on machines in the factory, and so on. With regarding these uncertainties, manufacturers could be resiliently responsive about their customers.

The aim of this research is to make an integrated decision in the whole of the supply chain under uncertainties due to reducing total tardiness in order to enhance competitive features. To meet this purpose, the following three steps are considered concurrently. First, supplier selection amongst suppliers to procure raw materials is carried out based on distance and delivery lead-time, which helps reduction in the main cost of finished products and delay. Second, using the CM as a manufacturing approach, contributes to reduction in delay and material handling cost in advance due to its nature. In addition, improvements in the $\mathrm{CF}$ and the cell management reduce the material handling time and the resource consumption, respectively, which in turn decreases delay. Lastly, this centralized decision will be improved sustainability of decision regarding demand, transfer time of shipping fleet, and processing time under uncertainty. These 
uncertainties make the integrated decision more realistic. Since any production plan is based on customers' demand. In most business environments, future demand is partly known at the best condition and occasionally is not clear at all [24]. Also, the transfer time of shipping fleet and processing time are uncertain because of traffic congestion, machine breakdown respectively and some unexpected events. Therefore, the mentioned uncertainties is essential to obtain a reliable solution. On the whole, this integrated decision under uncertainties leads to absorb customer goodwill thanks to good quality and low price of products along with sustainability. Hence, it raises the question that how to make this integrated decision including various delivery lead-times of suppliers, speeds of shipping fleets, configurations of cells, priorities of parts behind machines, and inter-cell movements of parts under uncertainties of demand, transfer time of shipping fleet, and processing time. So, the literature review consists of two parts in order to cover this paper. First, supply chain scheduling has been studied due to the coordination of suppliers, shipping fleets, and manufacturer. Second, the selected manufacturing approach has been reviewed owing to realize how researchers consider the priorities and inter-cell movements of parts along with the configurations of cells in the CM.

\section{Literature review \\ 1.1. The supply chain scheduling}

Supply chain scheduling causes decision makers at different stages of a supply chain to make coordinated decisions, which in turn increases efficiencies. It is presented for the first time by Hall and Potts [25]. They study various scheduling problems in which one supplier delivers materials to some manufacturers and also deliverers delivers products to customers. In their paper, objective function minimizes the total scheduling and delivery cost using numerous classical scheduling objectives such as a sum of completion times, maximum lateness, and number of late jobs. Owing to the applicability of this field, researchers continue supply chain scheduling. Some of the most relevant researches are presented. Selvarajah and Steiner [26] study two stages supply chain in order to find the optimal job sequence, number of batches, and batch sizes to provide customers' demand. They assume the amount of delivery cost depends on each delivered batch. A single supplier produces multiple products with a single machine, also a setup is required when changing from one product to another. Objective function minimizes a sum of the total inventory holding cost and the batch delivery cost from the viewpoint of the supplier. The scheduling problem that is considered both production and job delivery simultaneously, is studied by Wang and Cheng [27]. They consider machine availability as well. Their assumption is one vehicle is available to deliver jobs in fixed transportation time to a distribution center. The minimization of the arrival time for the last delivery batch to the distribution center is considered as the objective function. Production and transportation scheduling are integrated by Zegordi and Beheshti Nia [28] in a two-stage supply chain. They also assign orders to the suppliers. The first stage contains numerous suppliers distributed in different geographic regions, and the second stage consists of vehicles with various speeds and transportation capacities that transported jobs from the supplier to a manufacturing firm. The objective function of their paper is the minimization of makespan (i.e., the maximum completion time of all jobs). a two-phase mixed integer linear programming model is presented by Yimer and Demirli [29] for a build-to-order supply chain system to optimize material procurement, components of production, assembling of products and distribution scheduling. First, they decompose the problem into two phases. The first phase consists assembly and distribution scheduling of customizable products. The second phase includes production and procurement planning. The objective function of the first-phase model is the total cost for the assembling of products and distribution-subsystem and the objective function of the second-phase model is the total cost including the components of production and procurement subsystem. Zegordi et al. [30] study in the context of a two-stage supply chain environment in order to the scheduling of products and vehicles. The first stage consists suppliers with various production speeds and second stage includes vehicles with different speeds and transportation capacities to carry products from suppliers to a manufacturing company. Also, products have different batching sizes to occupy capacity of vehicle. Objective function minimizes the makespan of whole output products for all 
jobs. Steinrücke [31] discusses a real-life problem of a global aluminum supply chain network containing three supply chain stages. At each stage of the aluminum supply chain network, numerous members are involved which are located worldwide sites. The material flows amongst supply chain stages are transferred by a global shipping firm. The production capacities and transportation capacities differ from site to site. Their model minimizes total costs to coordinate production operations and material flows within the supply chain. Production and transportation costs along with bonus payments for early deliveries to final customers consider in the total costs. Maheut et al. [32] propose a model for operations of lot-sizing and scheduling, which includes an assignment and sequencing in the supply chain of an international company. The company produces and delivers made-to-order products through numerous distributed assembly plants geographically. Objective function minimizes a sum of the storage costs, the stroke execution costs and those costs associated with sequencing strokes. The stroke is a similar concept to the Resource-Task Networks to consider purchase, transport and production alternatives in the supply chain. Wang et al. [33] present an integrated scheduling problem for a single-item in make-to-order supply chain system with one supplier. Also, their supply chain system is considered one capacitated transporter, one customer, and a single machine in the production stage. Their non-liner model minimizes a sum of setup, delivery and inventory costs. Also, an intermediate inventory is assumed as a buffer to balance the production rate and the transportation speed. Ma et al. [34] investigate scheduling of production with shipping information simultaneously. Manufacturing model assumes a factory is located in one place and customers are overseas. They consider a manufacturing model along with shipping. Objective function minimizes the earliness and tardiness, which consists of storage, shipment, and tardiness. Hajiaghaei-Keshteli et al. [35] formulate the coordination problem of production and rail transportation. They develop a mathematical model to deliver orders from a facility to the warehouses. The model optimizes both production schedule and the rail transportation allocation of orders to available transportation capacities and also identify the sequence and completion time of these orders. Destinations and capacities of trains are different. This model minimizes the total cost including delivery earliness, delivery tardiness, and transportation. Cheng et al. [36] study a two-stage supply chain scheduling problems to optimize production and distribution of products. They assume the processing of a batch is non-preemption until all jobs in the batch are finished and machine capacity is limited. The finished jobs are categorized by the manufacturer and delivered to the customer by its own vehicles. Two types of machine configuration, single machine and parallel machines, are explored. The goal minimizes the time of production and delivery. Pei et al. [37] concentrate on a two-stage supply chain scheduling problem in an aluminum production. The extrusion factory of the supplier and the transportation from the supplier to the manufacturer are first stage, and the aging factory of the manufacturer is the second stage. A serial batching machine and a parallel batching machine process jobs in the first stage and the second stage, respectively. Meanwhile, only one vehicle transports jobs between two firms. The machines and vehicle have the specified capacity, and all jobs are processed as non-preemption in each batch. Their mixed integer programming model minimizes makespan. Cheng et al. [38] consider the scheduling of production and distribution for manufacturers. Machines with specified capacity process batches and jobs have constant sizes in the production stage. Jobs are clustered into batches and the processing of each batch could not be stopped until all its jobs are finished. All deliveries are transferred by a third-party logistic provider and vehicles have specified transportation capacity. The objective function minimizes the total cost of production and distribution. Pei et al. [39] discuss in the context of preemptive scheduling problem in a two-stage supply chain. The first stage is production stage where jobs are first divided into batches and then they process on a limited serial batching machine. Two situations are considered such as all jobs are available at time zero and they arrive with a release time. In the second stage, customer stage, a single vehicle carries each batch to a customer. The vehicle capacity was constant and it was equal to machine capacity. Objective function is to minimize the makespan of both problems. Assarzadegan and Rasti-Barzoki [40] present a mathematic model to study due date assignment, production scheduling, and outbound distribution scheduling, simultaneously. The model minimizes costs including maximum tardiness, due date assignment, and delivery for a single machine. Hassanzadeh and RastiBarzoki [41] research into supply chain scheduling and vehicle routing problem in order to decline the consumption of resources and energy and also tardiness penalty. They solve a bi-objective mathematical 
model to find the proper assembly sequence, assignment of orders to vehicles and vehicle routing in order to reduce resource consumption. The first objective function is minimization of the total tardiness cost and the second one minimizes the total amount of resources. Noroozi et al. [42] study coordination of order acceptance, batch delivery, and transportation. Orders are accepted or rejected based on distribution cost, capacity, tardiness cost, and sales revenue of each order. Single machine produces several products and they schedule in the production stage of supply chain. Then, products are batched and shipped to a respective customer by vehicles in the distribution stage. When the number of vehicles to carry products are less than they need, they use third-party logistics. The number of vehicles and capacity of them belong to the firm are constant in the customer stage. Objective function maximizes the difference between revenue from accepted orders and costs of tardiness and transportation. Wang et al. [43] investigate integrated production and distribution scheduling problem and multiple trips vehicle routing problem with time windows and uncertain travel times. They consider a processing site with parallel machines to produce a number of jobs and finished jobs are distributed by a fleet of identical vehicles, which demand of customers were known for each job. Jobs are assigned to the machines and the processing sequence of the jobs is determined on each machine in the production stage. Moreover, the completed jobs are assigned to the delivery vehicles and the vehicle routing is determined in the customer stage. The objective function minimizes the travel cost and penalty cost due to tardiness. Tang et al. [4] study a multi-factory supply chain scheduling in a collaborative manufacturing mode through considering transportation and production concurrently. They consider the urgency of various orders via a delivery time window with respect to least production and slack time. The objective function of their mixed integer programming model minimizes a sum of inventory cost, production cost, and the penalty costs of tardiness and early completion. Aminzadegan et al. [5] present a two-stage supply chain scheduling problem including two types of customers and one manufacturer. Providing that the tardiness penalty is paid by the manufacturer, the first customer admits tardiness in delivery of orders and the second customer does not admit the tardy orders. Manufacturer uses one machine and at any given moment, the machine can process one order at most. Each order is processed uninterruptedly. Objective function minimizes the sum of costs consisting of resource allocation, tardiness penalty, and batch delivery for the first customer, and the total number of tardy orders for the second customer.

\subsection{The CM}

The CM has been widely studied in the literature, so it narrows down by some of the most relevant researches as follows. Arkat et al. [44] present two mathematical models in order to investigate design of the CM system. First, the CF and cellular layout problems are solved simultaneously to minimize the total movement costs due to optimize cell configuration and the layout of the machines on the shop floor. Second, the cellular scheduling problem is solved based on the found solution in the first model as a job shop scheduling problem with the objective function of minimizing the total completion time of parts. They show the influences of considering cellular scheduling on the CM system design. Pasupuleti [45] present a methodology for detailed scheduling of all jobs in the CM systems with the given part families, the number of machines for each type of machine, and machine cells. The processing sequences of jobs, processing and setup times and due dates are considered along with different dispatching rules i.e., first come first serve, shortest processing time, longest processing time, earliest due date and least slack in their methodology. The methodology allocates jobs for each type of machine in each cell along with producing detailed schedules for each job. The considered dispatching rules are evaluated by different performance measures such as the makespan, mean flow time, mean lateness and mean tardiness. Arkat et al. [46] investigate three major decisions of the $\mathrm{CM}$ including the $\mathrm{CF}$, the layout of machines and the scheduling of operations concurrently. They propose a multi objective mathematical model that first objective function minimizes the total transportation cost of parts and second one minimizes the makespan. Kesen and Gungor [47] discuss job scheduling problem with lot-streaming strategy in virtual manufacturing cells. A virtual CM system includes a group of machines that is dedicated to produce a part family, but machines don't have to be near each other, i.e., they can be different places on the shop floor physically. Each job has its own processing sequences and there is a set of machines to process any operation of each job. They develop a 
mixed integer linear programming formulation that considers machine assignments, starting times and the sub-lot sizes of operations. Objective function minimizes the makespan due to the fact that machines are distributed through the facility and traveling times between each pair of machines are taken into account. Eguia et al. [48] investigate the CF and the scheduling of part families. A mixed integer linear programming model is presented which objective function minimizes production costs. These costs are related to the reconfigurable machine tools between two sequential families and the under-utilization of machines' resources while producing families. Solimanpur and Elmi [49] propose a mixed integer linear programming model for cell scheduling problem in order to minimize the makespan. They consider bottleneck machines and exceptional parts, processed part in multiple cells, in this model, because duplicated machines cause the decrease of intercellular movements. Taouji Hassanpour et al. [50] explore scheduling problem of jobs in virtual $\mathrm{CM}$ systems. Also, they assume that there are multiple jobs with different manufacturing processing routes. Objective function minimizes a sum of two weighed objectives including tardiness and total travelling distance. Saravanan and Karthikeyan [51] address the scheduling optimization problem of CM systems which consists of different manufacturing cells. First, Rank Order Clustering Method is used to identify and group into cells in order to the optimization of schedule for different types of products in the job-shop environment. Second, an optimization procedure is presented for sequencing of jobs to process in the machine cells. Objective function minimizes the penalty cost, when due dates have not met. Fahmy [52] presents a mixed integer linear programming model to formulate and solve combined CF, group layout, and group scheduling decision problem to design the CM system. Model takes into account intercellular and intracellular transportation time and sequence-dependent setup time to determine the optimal CF, candidate positions for machines within cells, distances between these positions and between cells to obtain the optimal group layout, and schedule of parts on machines, simultaneously. Objective function minimizes the mean flow time. Halat and Bashirzadeh [53] study the problem of operation scheduling with considering sequence-dependent family setup time, exceptional elements and intercellular transportation time in the CM systems concurrently. They propose an integer linear programming model that considers all aspects of the problem with the objective function of minimizing the makespan. Liu and Wang [54] group multifunctional machines and multi-skilled workers and assign them to cells. They present a nonlinear integer mathematical model, which simultaneously integrating the CF and task scheduling with dual-resource constrained setting. Objective function minimizes the makespan. Egilmez et al. [55] study family and job sequencing problem in the CM, where family splitting amongst cells is allowed. Each job is assumed to have individual due date and each family requires a setup before jobs in that family can be processed. This creates a natural conflict between meeting due dates of jobs and reducing total setup time. Objective functions minimizes total tardiness and the number of tardy jobs in a multi objective mathematical model. Rafiei et al. [56] research into the CF problem and group scheduling simultaneously in the presence of sequence-dependent setups in a job shop layout. They propose a mixed integer nonlinear program to cover issues with the objective function of minimizing the costs of operations and movement of both intercellular and intracellular paths simultaneously in a single-period setting. Liu et al. [57] investigate the CM system under dual-resource constrained setting with considering the CF and task scheduling, concurrently. They present a nonlinear 0-1 integer programming to minimize intercellular material handling cost, the fixed costs of machines and worker, and the operating costs of machines and workers. Also, they consider multifunctional machines, multi-skilled workers, and operation sequence. Deliktas et al. [58] propose four nonlinear multi objective models that deal with a flexible job shop scheduling problem in the CM environment. They consider exceptional parts, intercellular movements and transportation times, sequencedependent family setup time, and recirculation, a part may visit a machine or work center more than once. Objective function minimizes the makespan. Feng et al. [59] discuss a dynamic cellular scheduling problem with machine sharing, a machine may belong to more than one cell, and flexible routes. The makespan and the total workload are minimized by the multi objective mathematical model. Machines assign in different cells and the sequence of operations for each part determines in this model simultaneously. Feng et al. [60] integrate the $\mathrm{CF}$ and scheduling problem in the presence of substitute process routings, reentrant parts, duplicate machines and variable cell number. They minimize total completion time in order to form machine groups, determine cell number, generate optimal production schedule, and choose a suitable 
machine for each operation. Forghani and Fatemi Ghomi [61] design and configure a CM system integrating the $\mathrm{CF}$, group layout, and cell scheduling. They configure cells considering classical and virtual cells. The classical cell configuration arranges machines within cells and locates cells on the shop floor. Likewise, the virtual cell configuration uses to locate machines on the shop floor. They attempts to minimize a weighted sum of average cycle time and total handling costs in the presence of substitute processing routes.

In Error! Reference source not found., the brief review of literature in comparison with this research is presented. The type of supply chain stage, the scheduled component of supply chain, the uncertain component of supply chain, objective function, and solution method are determined in each research. To the best of authors' knowledge, a two-stage supply chain scheduling along with the cellular manufacturing in the production stage under uncertainties formulated by queuing theory has not been presented in the literature.

In this paper, significant aspects of supply chain scheduling along with the CM are considered to minimize total tardiness. In order to formulate this integrated decision, a mathematical model is presented. The modeling approaches of supply chain management include economic, deterministic analytical, stochastic, and simulation models [62]. Moreover, uncertainty in the CM could be classified according to the three approaches: stochastic programming, fuzzy programming, and robust optimization. In this research, a stochastic supply chain scheduling along with a stochastic cellular manufacturing in the production stage is presented. The interval between two successive arrivals of demand, processing time on machines, and transportation time of vehicles are uncertain. Queuing theory is used to formulate the uncertainties. Queuing theory formulates simple models with including randomness and using comparatively few data, while it is a powerful analytical tool [63]. Besides, a genetic algorithm owing to the discreteness of decision variables is used to handle the complexity of proposed model.

According to hierarchical decisions of the supply chain, decisions are categorized into four time horizons. Their order from a longer horizon to a shorter horizon includes strategic planning, tactical planning, operational planning, and operational execution planning. When moving from the strategic planning to the operational execution planning, the horizon of decisions shorten [64]. Moreover, this paper is used queuing theory approach with the steady-state for modeling, and thus the decision horizon is longer than operational planning. Then, the horizon of the decision in this research is tactical planning. The main contributions of this paper are as follows:

1- The problem considers the CF problem, cellular scheduling problem, transportation between the manufacturer and suppliers, and supplier selection in one mathematical model.

2- Processing time of each machine, the demand of parts, the transportation time of vehicles are uncertain.

3- The cellular scheduling problem usually investigated individually while it influences on the CF as presented in the literature review. They are formulated in this research simultaneously.

4- A genetic algorithm (GA) is presented to tackle the complexity of the model and solve the problem in logical time.

The rest of the article is arranged as follows: in Section 2, the statement and assumptions of the problem, the notation of the model, and the mathematical model are discussed. Linearization of the model is described in Section 3. Section 4 describes the developed solution approach. In Section 5, computational results are presented including a number of numerical results and the detailed analysis of a spare parts manufacturer for automobiles in order to examine the strength and performance of the proposed mathematical model. Finally, conclusions are discussed in Section 6.

\section{Insert table 1}

\section{Problem description}


In this section, a non-liner model is presented for supply chain with two stages. The first stage includes transportation and procurement, which vehicles with numerous speeds transport raw materials in transportation component of supply chain. The second component of the first stage includes suppliers with different delivery lead-times. The second stage is a factory. In the factory, machines group into cells and parts behind machines prioritize to process. The Error! Reference source not found. illustrates the problem.

A stochastic cell formation problem in production stage is described, which processing time of parts on machines is uncertain. The proposed model minimizes total tardiness to form the best cells. It leads to increase a number of parts processed in intra-cell and inter-cell movements of parts minimize.

\section{Insert Figure 1}

As it was mentioned earlier, queuing theory is used for formulating of the problem. In this paper, three steps are done to answer a demand and queuing systems are used in each step. The first step includes interval the order time of part by a customer to load raw materials from a supplier in the vehicle, which $\mathrm{M} / \mathrm{M} / \infty$ queuing system is used (see Error! Reference source not found.). Demand is represented as a customer in this queuing system. It is worthy to mention that loading time is ignored. The second step is from the respective supplier to the manufacturer, which $\mathrm{M} / \mathrm{M} / \infty$ queuing system is used. Raw materials of each part are considered as a customer (see Error! Reference source not found.). Meanwhile, the vehicle as a server is assumed in both $\mathrm{M} / \mathrm{M} / \infty$ queuing systems. The last step is considered the interval that raw materials receive in the factory to produce the finished part. $\mathrm{M} / \mathrm{M} / 1 / \infty / \mathrm{PR}$ queuing system is considered to this step (see Error! Reference source not found.) that each part as a customer and each machine as a server are assumed. Using these concepts, the arrival rate for each queuing system is less than the service rate in these queuing systems. Then, arrival rate is equal to output rate for each queuing system and the inter-arrival time in three queuing systems are distributed exponentially.

\section{Insert Figure 2}

\section{Insert Figure 3}

\section{Insert Figure 4}

As it was mentioned earlier, the transportation component in the first stage is assumed as $\mathrm{M} / \mathrm{M} / \infty$ queuing system, which the first $\mathrm{M}$ means the inter-arrival time described by the exponential distribution, the second $\mathrm{M}$ indicates the service time defined by the exponential distribution, and $\infty$ represents the number of servers that is infinite. The production stage is assumed as $\mathrm{M} / \mathrm{M} / 1 / \infty / \mathrm{PR}$ queuing system. The definition of first three symbols mentioned in $\mathrm{M} / \mathrm{M} / \infty$ queuing system. The rest of symbols are the restriction on system capacity and the queue discipline, respectively. The fourth symbol indicates no restriction on the system capacity. PR, which is a type of queue disciplines, means customers with the highest priorities are chosen for service ahead of those with lower priorities, independent of their time of arrival into the system. There are two more refinements possible in priority situations, namely, preemption and non-preemption. In this paper, non-preemption refinement is assumed. It means, there is no interruption and the highest- 
priority customer just goes to the head of the queue to wait its turn. Meanwhile, each machine as a server and each part as a customer are considered where servers should service to customers.

As it was mentioned earlier, the transportation component is assumed as a queuing system, which there is the unlimited service because the infinite number of vehicles is available. The number of vehicles is unlimited whereas the type of vehicles is a certain number. Each type of vehicles has a constant speed. Demand for part $i$ arrives with rate $\lambda_{i}$ where one of the vehicles with the rate $\mu_{v}$ picks up raw materials from the respective supplier. The average waiting time in the system is $\frac{1}{\mu_{v}}$ as well. Meanwhile, return route from supplier to the manufacturer is considered the same queuing system. It should be mentioned, each supplier only produces raw materials of the certain part. At the production stage, parts of the kth priority arrive at a single channel queue according to a Poisson process with rate $\lambda_{k}(1 \leq k \leq N)$ and these parts wait on a first-come, first-served basis within their relevant priorities. It should be noted, the smaller number for $k$ shows the higher priority. Also, the service distribution for the kth priority is exponential with mean $\frac{1}{\mu_{k}}$. Meanwhile, the average waiting time in queue for $i$-priority part in the production stage defined as follow (for further details on the queuing system in this section, see also [65] ):

$$
W_{q}^{(i)}=\frac{\sum_{k=1}^{N} \frac{\rho_{k}}{\mu_{k}}}{\left(1-\sigma_{i-1}\right)\left(1-\sigma_{i}\right)}
$$

Where $\rho_{k}=\frac{\lambda_{k}}{\mu_{k}} 1 \leq k \leq N$ is called utilization factor, $\sigma_{k}=\sum_{i=1}^{k} \rho_{i}, \sigma_{0}=0$, and the system is stationary for $\sigma_{N}<1$.

\section{Index}

$i$ : Index for parts $i=1,2, \ldots, P$

$j, u$ : Index for machines $j, u=1,2, \ldots, M$

$v$ : Index for types of vehicles $v=1,2, \ldots, V$

$s:$ Index of suppliers $s=1,2, \ldots, S$

$p, r$ Index of priorities $p, r=1,2, \ldots, N$

$o$ : Index of operations $o=1,2, \ldots, O_{i}$

$k$ : Index of cells $k=1,2, \ldots, C$

\section{Parameters}

$R_{i s}$ : Delivery lead-time of supplier $s$ for part $i$ 
$\lambda_{i}$ : Demand rate of part $i$ for a given planning horizon

$\mu_{j i}$ : Mean service rate of machine $j$ for part $i$

$\mu_{v s}^{\prime}:$ Mean service rate of vehicle $v$ for supplier $s$

$L:$ A sufficiently large number

$O_{i}$ :The number of operations for part $i$

$M_{\max }$ : The largest number of machines permitted for each cell

$d_{i}$ : The due date of part $i$

$a_{i o j}: 1$ if the operation $o$ of part $i$ is processed on machine $j$ and 0 otherwise

$\tau$ :Inter-cell movement time of each part in order to process on required machines

\section{Decision variables}

$c_{1 i}$ : Mean completion time of raw materials for part $i$, the interval between the order time of part $i$ by a customer and loaded vehicle(s) ready to carry raw materials (first component of first stage)

$c_{2 i}$ :Mean procurement time of raw materials for part $i$, from the order time of part $i$ by a customer to arrival time in the manufacturer (first stage)

$c_{3 i}$ : Mean completion time of part $i$ (from the order time of part $i$ to finished part)

$S U_{s i}: 1$ if part $i$ is supplied by supplier $s$ and 0 otherwise

$G_{v i}: 1$ if part $i$ is picked up by vehicle $v$ and 0 otherwise

$P R_{i p}: 1$ if part $i$ assigned to priority $p$ and 0 otherwise

$y_{j k}: 1$ if machine $j$ assigned to cell $k$ and 0 otherwise

\section{Model formulation}

The queuing system in the manufacturer has to be stable, i.e., the service rate must be necessarily more than the arrival rate. Hence, amounts of used parameters in the mathematical model consider the stability condition of queuing system related to the manufacturer. The stabilizing equation (2) will be elaborated in this subsection. The following equation avoids the infinite queue length behind of each machine:

$$
\sum_{i=1}^{P} \frac{\lambda_{i} \sum_{o=1}^{o_{i}} a_{i o j}}{\mu_{j i}}<1 \quad \forall j
$$

The mathematical model is formulated as below: 
$\operatorname{Min} Z=\sum_{i=1}^{P} \max \left\{0, c_{3 i}-d_{i}\right\}$

The objective function (3) minimizes total mean tardiness.

$S . T: \sum_{s=1}^{S} S U_{s i}=1 \quad \forall i$

Constraint (4) guarantees that each part must be assigned to one supplier.

$S U_{s i} \leq L \times R_{i s} \quad \forall s, i$

Constraint (5) causes that one supplier selects amongst suppliers with the production capability of raw materials for part $i$ (i.e., $R_{i s}>0$ ).

$\sum_{v=1}^{V} G_{v i}=1 \quad \forall i$

Constraint (6) makes sure that each part assign to one type of vehicles.

$c_{1 i} \geq \sum_{s=1}^{S} \sum_{v=1}^{V} \frac{1}{\mu_{v s}^{\prime}} S U_{s i} G_{v i} \quad \forall i$

As it was mentioned above, the waiting time in system for $M / M / \infty$ queuing system is mean service time. Then, constraint (7) shows that the mean completion time of raw materials for each part in the relevant supplier (i.e., $c_{1 i}$ ) is at least equal to the mean service time of vehicle.

$$
\begin{array}{ll}
\sum_{i=1}^{P} P R_{i p}=1 & \forall p \\
\sum_{p=1}^{N} P R_{i p}=1 & \forall i
\end{array}
$$

Constraints (8) and (9) assign each priority to one part.

$c_{1 i} \geq \sum_{s=1}^{S} R_{i s} S U_{s i} \quad \forall i$

Constraint (10) ensures that the mean completion time of raw materials in the respective supplier for each part is bigger than the delivery lead-time of the same supplier.

$c_{2 i} \geq c_{1 i}+\sum_{s=1}^{S} \sum_{v=1}^{V} \frac{1}{\mu_{v s}^{\prime}} G_{v i} S U_{s i} \quad \forall i$

Constraint (11) guarantees that the mean procurement time of raw materials is larger than the mean completion time of raw materials in the respective supplier plus mean transportation time from the respective supplier to the manufacturer for each part.

$\sum_{k=1}^{C} y_{j k}=1 \quad \forall j$

Constraint (12) makes sure that each machine assign only to one cell. 
$\sum_{j=1}^{M} y_{j k} \leq M_{\max } \quad \forall k$

Constraint (13) ensures that maximum number of machines will not exceed certain amount $M_{\max }$.

$c_{3 i} \geq c_{2 i}+$

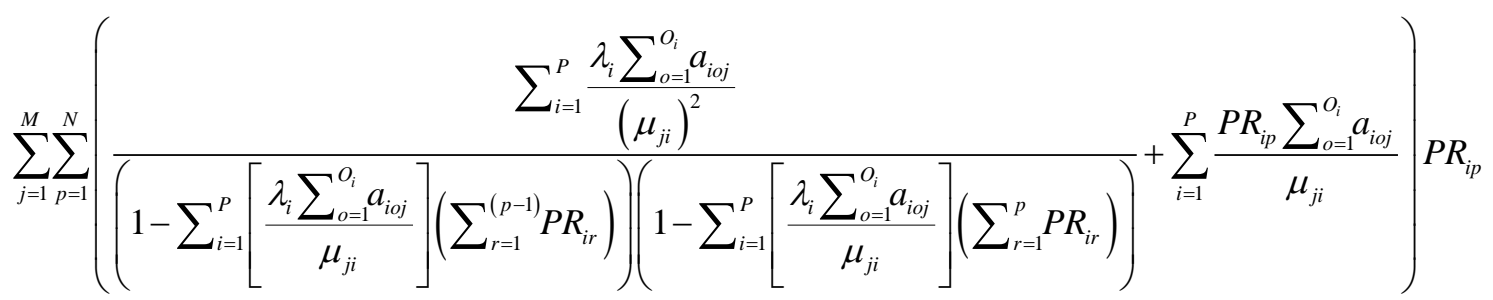

$+\sum_{j=1}^{M} \sum_{\substack{u=1 \\ u \neq j}}^{M} \sum_{k=1}^{c} \sum_{o=1}^{\left(o_{i}-1\right)} \tau\left(a_{i j j} y_{j k}\right)\left(a_{i(o+1) u}\left(1-y_{u k}\right)\right) \quad \forall i$

Constraint (14) indicates the mean completion time of part $i$ (i.e., $c_{3 i}$ ) is summation of the mean procurement time of raw materials for part $i$ (i.e., $c_{2 i}$ ), the mean waiting time of part $i$ in the manufacturer stage, and inter-cell movement time of part $i$. The mean waiting time of each part in the manufacturer stage includes two terms. The first term in the parentheses indicates the mean waiting time of $p$-priority part in queue behind machine $j$. Term $\left[\frac{\lambda_{i} \sum_{o=1}^{o_{i}} a_{i o j}}{\mu_{j i}}\right]$ represents the utilization factor of machine $j$ to process part $i$, which term $\sum_{o=1}^{O_{i}} a_{i o j}$ indicates the number of operations of part $i$ on machine $j$. The utilization factor machine $j$ to process $p$-priority part is obtained by multiplying term $\left[\frac{\lambda_{i} \sum_{o=1}^{o_{i}} a_{i o j}}{\mu_{j i}}\right]$ by $P R_{i r}$. Therefore, term $\sigma_{p-1}$ in equation (1) is equal to $\sum_{r=1}^{(p-1)}\left(\sum_{i=1}^{P}\left(\left[\frac{\lambda_{i} \sum_{o=1}^{o_{i}} a_{i o j}}{\mu_{j i}}\right] \times P R_{i r}\right)\right)$, and it is rewritten to term $\sum_{i=1}^{P}\left[\frac{\lambda_{i} \sum_{o=1}^{O_{i}} a_{i o j}}{\mu_{j i}}\right]\left(\sum_{r=1}^{(p-1)} P R_{i r}\right)$ in constraint (14). The second term in the parentheses of the mean waiting time of each part in the manufacturer stage is the mean processing time for $p$-priority part on machine $j$. Ultimately, the sum of two terms in the parentheses of the mean waiting time of each part multiplies by $P R_{i p}$, which means the mean waiting time of part $i$ to process on machine $j$. The third term of constraint (14) means if the next operation of certain part processes in another cell, it causes the inter-cell movement of the same part. It should be noted, intra-cell movement time is neglected.

$$
S U_{s i}, G_{v i}, P R_{i p}, y_{j k} \in\{0,1\}, c_{1 i}, c_{2 i}, c_{3 i} \geq 0 \quad \forall s, i, v, p, j, k, o
$$

Constraint (15) defines the ranges of the decision variables. 
In the following, the stabilizing equation (2) is explained. The utilization factor for each machine in the manufacturer stage has to be less than 1 to avoid instability of the queuing system. Furthermore, the utilization factor for machine $j, \rho_{j}$, is equal to the arrival rate divided by service rate [65]. Also, the arrival rate of machine $j$ is $\sum_{i} \lambda_{i}$, because the part arrival time to process on machine $j$ is equivalent to the most minimization of the arrival time of parts needed to be processed on machine $j$. Moreover, the inter-arrival time between two successive parts has exponential distribution, then the most minimization of the part arrival time to process has an exponential distribution with parameter $\sum_{i} \lambda_{i}$. Ultimately, $\rho_{j}=\sum_{k=1}^{C} \frac{\sum_{i=1}^{P} \sum_{o=1}^{o_{i}} \lambda_{i} a_{i j} y_{j k}}{\mu_{j i}} \quad \forall j$ is rewritten using equation (12), $\sum_{k=1}^{c} y_{j k}=1 \quad \forall j$, to find the equation (2).

\section{Linearization}

The proposed model is a nonlinear mathematical model. Hence, three steps are used to linearize the proposed model. In the first step, the objective function (3) is linearized with defining new variable $C D I_{i} \geq 0$, which is equal to $\max _{i}\left\{0, c_{3 i}-d_{i}\right\}$. Constraints (18) and (19) are added to the proposed model for the linearization of the objective function (3). In the second step, new binary variable $S U G_{s v i}$ is replaced by $S U_{s i} \times G_{v i}$ for the linearization of constraints (7) and (11), and constraints (21) and (22) are added to the proposed model. In the third step, constraint (14) are broken down into four segments in order to linearize. First, the mean waiting time of $p$-priority part in the queue behind machine $j$ is linearized with intro ducing variable $W T_{j p} \geq 0$ which is equal to:

$$
W T_{j p}=\frac{\sum_{i=1}^{P} \frac{\lambda_{i} \sum_{o=1}^{O_{i}} a_{i o j}}{\left(\mu_{j i}\right)^{2}}}{\left(1-\sum_{i=1}^{P}\left[\frac{\lambda_{i} \sum_{o=1}^{O_{i}} a_{i o j}}{\mu_{j i}}\right]\left(\sum_{r=1}^{(p-1)} P R_{i r}\right)\right)\left(1-\sum_{i=1}^{P}\left[\frac{\lambda_{i} \sum_{o=1}^{O_{i}} a_{i o j}}{\mu_{j i}}\right]\left(\sum_{r=1}^{p} P R_{i r}\right)\right)} \quad \forall j, p
$$

The new auxiliary variables $Q_{j p i r} \geq 0,, T P R_{q t r} \cdot\left\{\{0,1\}, W P R_{j p i(q q)(t)} \geq 0, D P R_{i(q q)(t t)} \in\{0,1\}\right.$ are presented in order to linearize $W S P R_{j p i i r} \geq 0$, and $S P R_{i i{ }^{\prime} p r} \in\{0,1\}, W R_{j p i} \geq 0, W T P R_{j p q t r^{\prime}} \geq 0$ equation (16). Also, the relevant constraints (24)-(45) are added. Second, the mean processing time for part $i$ on machine $j$ is obtained via multiplying the mean processing time for $p$-priority part on machine $j$ by $P R_{i p}$. It is linearized by defining new variable $M P R_{i i p} \in\{0,1\}$ which is equal to $P R_{i p} \times P R_{i p}$ and adding constraints (46) and (47) in the proposed model. Third, the third term of the constraint (14), the inter-cell movement time of parts, is linearized. New variable $t y_{j u k} \in\{0,1\}$ is defined and two constraints (48) and (49) are added. Fourth, constraint (14) is replaced by constraint 
(50). Finally, the linearization of the mathematical model based on the direct decision variables is presented as follows:

$$
\begin{array}{ll}
\operatorname{Min} Z=\sum_{i=1}^{P} C D I_{i} & \\
S . T: C D I_{i} \geq 0 & \forall i \\
C D I_{i} \geq c_{3 i}-d_{i} & \forall i
\end{array}
$$

Constraints (4)-(6)

$$
\begin{aligned}
& c_{1 i} \geq \sum_{s=1}^{S} \sum_{v=1}^{V} \frac{1}{\mu_{v s}^{\prime}} S U G_{s v i} \quad \forall i \\
& S U G_{s v i}-S U_{s i}-G_{v i}+1.5 \geq 0 \quad \forall s, v, i \\
& 1.5 S U G_{s v i}-S U_{s i}-G_{v i} \leq 0 \quad \forall s, v, i
\end{aligned}
$$

Constraints (8)-(10)

$$
c_{2 i} \geq c_{1 i}+\sum_{s=1}^{S} \sum_{v=1}^{V} \frac{1}{\mu_{v s}^{\prime}} S U G_{s v i} \quad \forall i
$$

Constraints (12) and (13)

$$
\begin{aligned}
& W T_{j p}-2 \sum_{i=1}^{P}\left(\left(\frac{\lambda_{i} \sum_{o=1}^{O_{i}} a_{i o j}}{\mu_{j i}}\right)\left(\sum_{r=1}^{p} Q_{j p i r}\right)\right) \\
& +\sum_{i=1}^{P}\left(\left(\frac{\lambda_{i} \sum_{o=1}^{o_{i}} a_{i o j}}{\mu_{j i}}\right)^{2}\left(\sum_{r=1}^{p} Q_{j p i r}+2 \sum_{t t=1}^{p} \sum_{q q=1}^{t t-1} W P R_{j p i(q q)(t t)}\right)\right) \\
& +2 \sum_{t=1}^{P} \sum_{q=1}^{t-1}\left(\left(\frac{\lambda_{q} \sum_{o=1}^{o_{i}} a_{q o j}}{\mu_{j q}}\right)\left(\frac{\lambda_{t} \sum_{o=1}^{O_{i}} a_{t o j}}{\mu_{j t}}\right) \sum_{r^{\prime}=1}^{P} \sum_{r^{\prime}=1}^{P} W T P R_{j p q t r^{\prime} r^{\prime \prime}}\right) \\
& +\sum_{i=1}^{P}\left(\frac{\lambda_{i} \sum_{o=1}^{o_{i}} a_{i o j}}{\mu_{j i}}\right) W R_{j p i} \\
& -\sum_{i=1}^{P} \sum_{i^{\prime \prime}=1}^{P}\left(\left(\frac{\lambda_{i} \sum_{o=1}^{O_{i}} a_{i o j}}{\mu_{j i}}\right)\left(\frac{\lambda_{i^{\prime}} \sum_{o=1}^{O_{i}} a_{i^{\prime \prime} o j}}{\mu_{j i}}\right) \sum_{r=1}^{p} W S P R_{j p i i^{\prime \prime} r}\right) \\
& =\sum_{i=1}^{P} \frac{\lambda_{i} \sum_{o=1}^{o_{i}} a_{i o j}}{\left(\mu_{j i}\right)^{2}} \quad \forall j, p \\
& Q_{j p i r}=W T_{j p} \times P R_{i r} \quad \forall j, p, i ; r=1,2, \ldots, p \\
& Q_{j p i r} \leq L \times P R_{i r} \quad \forall j, p, i, r \\
& Q_{j p i r} \leq W T_{j p} \quad \forall j, p, i, r
\end{aligned}
$$




$$
Q_{j p i r} \geq W T_{j p}-\left(1-P R_{i r}\right) \times L \quad \forall j, p, i, r
$$

$$
\begin{aligned}
& D P R_{i(q q)(t t)}=P R_{i(q q)} \times P R_{i(t t)} \quad \forall i ; q q=1,2, \ldots,(t t-1) ; t t=1,2, \ldots, p \\
& D P R_{i(q q)(t t)}-P R_{i(q q)}-P R_{i(t t)}+1.5 \geq 0 \quad \forall i ; q q=1,2, \ldots,(t t-1) ; t t=1,2, \ldots, p
\end{aligned}
$$

$1.5 D P R_{i(q q)(t t)}-P R_{i(q q)}-P R_{i(t t)} \leq 0 \quad \forall i ; q q=1,2, \ldots,(t t-1) ; t t=1,2, \ldots, p$

$W P R_{j p i(q q)(t t)}=W T_{j p} \times D P R_{i(q q)(t)} \quad \forall j, p, i ; q q=1,2, \ldots,(t t-1) ; t t=1,2, \ldots, p$

$W P R_{j p i(q q)(t t)} \leq L \times D P R_{i(q q)(t t)} \quad \forall i ; q q=1,2, \ldots,(t t-1) ; t t=1,2, \ldots, p$

$W P R_{j p i(q q)(t t)} \leq W T_{j p} \quad \forall i ; q q=1,2, \ldots,(t t-1) ; t t=1,2, \ldots, p$

$W P R_{j p i(q q)(t t)} \geq W T_{j p}-\left(1-D P R_{i(q q)(t t)}\right) \times L \quad \forall i ; q q=1,2, \ldots,(t t-1) ; t t=1,2, \ldots, p$

$T P R_{q t r^{\prime} r^{\prime}}=P R_{q r^{\prime}} \times P R_{t r^{\prime}} \quad \forall r^{\prime}, r^{\prime \prime} ; t=1,2, \ldots, P ; q=1,2, \ldots,(t-1)$

$T P R_{q t r^{\prime} r^{\prime}}-P R_{q r^{\prime}}-P R_{t r^{\prime}}+1.5 \geq 0 \quad \forall r^{\prime}, r^{\prime \prime} ; t=1,2, \ldots, P ; q=1,2, \ldots,(t-1)$

$1.5 T P R_{q t r^{\prime} r^{\prime}}-P R_{q r^{\prime}}-P R_{t r^{\prime}} \leq 0 \quad \forall r^{\prime}, r^{\prime \prime} ; t=1,2, \ldots, P ; q=1,2, \ldots,(t-1)$

$W T P R_{j p q t r^{\prime}}=W T_{j p} \times T P R_{q t r^{\prime} r^{\prime}} \quad \forall r^{\prime}, r=1,2, \ldots, p ; \forall t=1,2, \ldots, P ; \forall q=1,2, \ldots,(t-1) ; \forall q, p$

$W T P R_{j p q t r^{\prime}} \leq L \times T P R_{q t r^{\prime} r^{\prime}} \quad \forall j ; p ; q ; t ; r^{\prime} ; r^{\prime \prime}$

$W T P R_{j p q t r^{\prime}} \leq W T_{j p} \quad \forall j ; p ; q ; t ; r^{\prime} ; r^{\prime \prime}$

$W T P R_{j p q t r^{\prime \prime}} \geq W T_{j p}-\left(1-T P R_{q t r^{\prime \prime}}\right) \times L \quad \forall j ; p ; q ; t ; r^{\prime} ; r^{\prime \prime}$

$W R_{j p i}=W T_{j p} \times P R_{i p} \quad \forall j ; p ; i$

$W R_{j p i} \leq L \times P R_{i p} \quad \forall j ; p ; i$

$W R_{j p i} \leq W T_{j p} \quad \forall j ; p ; i$

$W R_{j p i} \leq W T_{j p}-\left(1-P R_{i p}\right) \times L \quad \forall j ; p ; i$

$S P R_{i i^{\prime} p r}=P R_{i p} \times P R_{i r} \quad \forall i i^{\prime \prime}=1,2, \ldots, P ; \forall p ; \forall r=1,2, \ldots, p$

$S P R_{i i p^{\prime \prime} r}-P R_{i p}-P R_{i r}+1.5 \geq 0 \quad \forall i^{\prime}, i^{\prime \prime}=1,2, \ldots, P ; \forall p ; \forall r=1,2, \ldots, p$

$1.5 S P R_{i i^{\prime \prime} p r}-P R_{i p}-P R_{i r} \leq 0 \quad \forall i^{\prime}, i^{\prime \prime}=1,2, \ldots, P ; \forall p ; \forall r=1,2, \ldots, p$

$W S P R_{j p i i^{i r}}=W T_{j p} \times S P R_{i i^{i p r}} \quad \forall j ; p ; \forall i^{\prime}, i^{\prime \prime}=1,2, \ldots, P$

$W S P R_{j p i i r} \leq L \times S P R_{i i p r} \quad \forall j ; p ; \forall i, i "=1,2, \ldots, P$

$W S P R_{j p i i r} \leq W T_{j p} \quad \forall j ; p ; \forall i^{\prime}, i^{\prime \prime}=1,2, \ldots, P$

$W S P R_{j p i i^{\prime i}} \geq W T_{j p}-\left(1-S P R_{i i^{\prime p} r}\right) \times L \quad \forall j ; p ; \forall i^{\prime}, i^{\prime \prime}=1,2, \ldots, P$

$M P R_{i i p}-P R_{i p}-P R_{i p}+1.5 \geq 0 \quad \forall i, i^{\prime}=1,2, \ldots, P ; \forall p=1,2, \ldots, N$

$1.5 M P R_{i i p}-P R_{i p}-P R_{i p} \leq 0 \quad \forall i, i^{\prime}=1,2, \ldots, P ; \forall p=1,2, \ldots, N$

$t y_{j u k}=y_{j k} \times y_{u k} \quad \forall u, j, k, \quad u \neq j$

$t y_{j u k}-y_{j k}-y_{u k}+1.5 \geq 0 \quad \forall u, j, k, \quad u \neq j$ 


$$
\begin{aligned}
& 1.5 t y_{j u k}-y_{j k}-y_{u k} \leq 0 \quad \forall u, j, k, \quad u \neq j \\
& c_{3 i} \geq c_{2 i}+\sum_{j=1}^{M} \sum_{p=1}^{N}\left(W R_{j p i}+\sum_{i=1}^{P} \frac{M P R_{i i p} \sum_{o=1}^{O_{i}} a_{i o j}}{\mu_{j i^{\prime}}}\right) \\
& +\sum_{j=1}^{M} \sum_{\substack{u=1 \\
u \neq j}}^{M} \sum_{\substack{k=1 \\
k^{\prime}=1 \\
k=k^{\prime}}}^{C} \sum_{o=1}^{C} \tau_{\left.k k^{\prime}-1\right)} a_{i o j} a_{i(o+1) u} t y_{j u k k^{\prime}} \quad \forall i
\end{aligned}
$$

\section{Solution approach}

The NP-hardness of the CF problem is proved by some researchers ([66] and [67]). Hence, our more general problem is NP-hard as well. One of well-known methods to solve such problem is meta-heuristic algorithms. Besides, the discreteness of decision variables motivates to choose genetic algorithm (GA) among meta-heuristic algorithms to solve the mentioned problem. An overview of our framework is illustrated in Error! Reference source not found..

\section{Insert Figure 5}

The structure of solution or so-called chromosome in the GA is in the form of a matrix with 1 row and $3 \times P+M$ ( $M$ is the number of machines and $P$ is the number of parts) columns. The structure of chromosome is illustrated in Error! Reference source not found.. The first $p$ (index for the number of parts) arrays of the matrix are filled with the assigned type of vehicles to transport. The second $p$ arrays of the matrix are selected suppliers to produce raw materials of parts. The next $m$ (index for the machine number) positions of the matrix are filled by the assigned cell number so that each machine is located only in one cell. The last $p$ arrays of the matrix are the priorities of parts, which each part is assigned to only one priority.

\section{Insert Figure 6}

\subsection{Population initialization}

Initial population is generated as a set of feasible solutions. Steps of initial solutions are shown in Error! Reference source not found..

\section{Insert Figure 7}

\subsection{Fitness function}

A fitness function measures the chromosomes in the population. A fraction or whole of the better chromosomes is chosen for the next iteration generation. The objective function of proposed model is the fitness function in this research. It should be noted, the new generation is called offspring or children in the GA and each chromosome respects to all constraints of the proposed model.

\subsection{Selection method}

Tournament selection is the selection strategy in the proposed algorithm. It selects the fittest chromosomes from the current generation to use in the next generation. First, a certain number of 
chromosomes is chosen randomly. Second, it is run a tournament among them based on fitness function. Lastly, the best one is selected that moves on to use in the crossover operator. When the tournament size is large, it is possible chromosomes with weak fitness functions to compete with stronger ones.

\subsection{Crossover operator}

A crossover operator replaces data from two parents and generates children from them. These children inherit some segments from their parents. In this paper, one-point crossover is chosen among crossover mechanisms to generate children. An example based on our solution structure is presented to clarify the mechanism of one-point crossover in Error! Reference source not found.. It should be noted, last segment of chromosome, the priorities of parts, isn't considered to the crossover mechanism. The one-point crossover replaces genes of parents with each other to generate children from both parents.

\section{Insert Figure 8}

\subsection{Mutation operator}

Mutation keeps one or more genes from current generation to the next. A single point mutation operator is used in this research. A random number between 1 to $3 \times P+M$ is generated for the mutation operator. If the number is between 1 to $2 \times P+M$, the selected gene will be changed to another one with relative features. For instance, if the number is less than $P$, then another vehicle replaces. As it was mentioned, the chromosome has 4 segments. Last segment is a permutation of parts. Therefore, if the number is larger than $2 \times P+M$, then another gene randomly in this segment is selected to swap places. Error! Reference source not found. clarifies the mechanism of the single point mutation.

\section{Insert Figure 9}

\section{Computational results}

Taguchi method is performed to set parameters since the efficiency of the meta-heuristics algorithms depends toughly on parameters. The importance of each setting parameter and the interactions between them are estimated by this technique. It should be noticed, the test problems are categorized in three groups including small, medium, and large scale. The test problems 2, 5, and 8 are selected from examples to cover different scales. After a large number of tests, a range of data is assumed for each parameter of the GA to estimate an appropriate value (see Error! Reference source not found.). The results of the Taguchi experiment show small, medium, and large scale experiments, respectively.

\section{Insert Table 2}

Nine test problems that are presented in Error! Reference source not found. are considered to evaluate the adequacy of the model and the performance of the GA. The small scale test problems have been selected from the literature ([44] and [68]) and the rest of test problems have been generated randomly. The proposed model and GA have been coded in the Lingo 12.0 and 
MATLAB 2013a, respectively. They have solved on a computer with 2.99 GB RAM and core i5 with $2.50 \mathrm{GHz}$ processor.

The test problems have been solved by branch and bound (B\&B) of Lingo software and the GA. Then, the results of them compare with each other in Error! Reference source not found.. Large scale test problems have been allowed to run for $5400 \mathrm{~s}$ or $1.5 \mathrm{~h}$. Each test problem was run 3 times by the GA, and then the average of solutions in $Z_{\text {ave }}$ and the best solution in $Z_{\text {best }}$ were reported. According to the tutorial of Lingo software, $F_{\text {best }}$ is the best amount of the objective function that has been ever found and $F_{\text {bound }}$ is the objective function of dual model that is obtained through primary model. If $F_{\text {bound }}$ is equal to $F_{\text {best }}$, the objective function achieves the global optimal solution. Furthermore, for large scale test problems if $Z_{\text {ave }}$ or $Z_{\text {best }}$ is between $F_{\text {bound }}$ and $F_{\text {best }}$, it means the GA has obtained better solution than the B\&B of Lingo software. Also, if the GA achieves $F_{\text {bound }}$ in the proposed model, it obtains the global optimal solution. Because $F_{\text {bound }}$ is the least possible amount of the objective function for the primary model obtained by the B\&B of Lingo software. Using these concepts, it is worthy to mention that suitable metrics are an essential which can provide a base for comparing results and claiming to obtain reliable solutions. For this manner, standard deviation (SD) is used. The small amount of SD means the GA can provide reliable solutions.

The results of the GA and the B\&B of Lingo software are shown in Error! Reference source not found. The results depict for the small scale problems, the B\&B of Lingo software and the GA reach the same results except problem 3 with small deviation. The B\&B of Lingo software and the GA show good agreement for the medium scale problems in the Error! Reference source not found. The results depict that the GA can provide better solution in the large scale problems (see Error! Reference source not found.). The B\&B of Lingo software consumes and requires much more time than the GA. In addition, the SD of solutions is small as shown in Error! Reference source not found. which means the GA can provide reliable solutions. Error! Reference source not found. shows the minimizing process for the test problem 5 using the GA.

\section{Insert Table 3}

\section{Insert Figure 10}

\section{Insert Figure 11}

\subsection{A case study}

The model is employed in a spare parts manufacturer for automobiles which is located in Tehran, Iran. In this case, the cell number is five, $M_{\max }$ is six, four type of spare parts for automobiles produce in the manufacturer, eight suppliers supply raw materials of parts, five vehicle types are available to carry raw materials, inter-cell movement time of each part is 10, machines assign to five cells and the rest of the case information is presented in Appendix A.

The following results are obtained by solving the case study. The vehicle type 1 is assigned to carry the raw materials of all parts, the raw materials of parts 1 to 4 are supplied by suppliers 1,7 , 
2 , and 8 , respectively, the priorities of parts 1 to 4 are in order $1,4,3$, and 2 to process on machines, and Error! Reference source not found. shows assigned machines to cells.

Each row in each cell shows the queue of parts in Error! Reference source not found. in order to process on the respective machine based on the solution. Also, each part in the queue waits to process based on its priority.

It could be more than one type of parts in each queue. But it is refused because the figure looks messy. Each type of parts is shown by a certain shape and the process flow of each part could be followed by the numbers on the inside of shapes. As you see in the figure, the number of inter-cell movements are less than intra-cell movements, which proves the high performance of the proposed model. As you can see, the main factor in the configuration of cells is $M_{\max }$, that prevents more than six machines in each cell.

\section{Insert Table 4}

\section{Insert Figure 12}

\subsection{Sensitivity analysis}

The case study is considered for sensitivity analysis of the proposed model to highlight important managerial insights such as coordination of supply chain. The delivery lead-time of candidate suppliers $\left(R_{i s}\right)$ for part 4 is changed and kept the other parameters fixed to analyze the effect of change on the mean waiting and inter-cell movement time of part 4 . The behavior of the model is investigated through multiplying $R_{4 s}$ for all candidate suppliers by different numbers (X). How the mean waiting and inter-cell movement time behave are depicted in the Error! Reference source not found.. While $X$ boosts, the mean waiting time reduces and it leads to decrease the priority of part 4 as well. Since, the mean waiting time impacts on the delay. Increasing of the delivery lead-time of candidate suppliers for part 4 not only influences on the mean waiting time, but it also influences on inter-cell movement time. So, it reduces inter-cell movement time by trying to assign all operations of part 4 in one cell. It may not decrease the mean waiting and intercell movement time for part 4 simultaneously, as X increases. However, that reduces total mean waiting and inter-cell movement time for part 4 if it is not in the least possible amount. The threshold of this reduction for part 4 while $\mathrm{X}$ increases is the shortest total mean waiting and intercell movement time for part 4 in order to reduce the delay of part 4.

The results showed when the delivery lead-time of candidate suppliers for the specific part increases, it causes a reduction in the sum of mean waiting and inter-cell movement time for that part, until there is no delay for the other parts. This reduction in the mean waiting and inter-cell movement time for the specific part may increase the mean waiting time or inter-cell movement time of the other parts. It may happen due to the fact that the model attempts to assign all operations of the specific part in one cell and push other parts out of the cell. Those need to operate on the same machine(s). Also, it might increase the mean waiting time of parts other than the specific part so that the specific part takes short mean waiting time. 


\section{Insert Figure 13}

\section{Conclusion}

In this study, a two-stage supply chain scheduling was presented. The first stage, supply, is considered vehicles with various speeds to transport raw materials and suppliers with different delivery lead-times. Production, the second stage, is investigated the assignment of machines to cells and the identification of the priority of each part to process on the relevant machine. In other words, the CF problem along with the scheduling of each part within cells are studied. In this paper, demand, processing time on machines, and the transportation time of vehicles have an exponential distribution. A novel mixed-integer nonlinear mathematical model is developed with the queuing theory framework to find the mentioned issues based on the minimization of total tardiness as the objective function. In order to find exact solutions, the nonlinear mathematical model is linearized. A GA is developed to cope with such NP-hard problem. Moreover, Taguchi's experimental design method is used to set the proper values for the parameters of the GA to improve its performance. The performance of the model and the GA are tested by solving test problems with different sizes. The GA solved all the test problems within a very short period of computational time. However, the linearized mathematical model, which has been coded using Lingo software, could not provide an optimal solution to the large scale test problems within $1.5 \mathrm{~h}$. The proposed mathematical model is employed in a real case. The acquired results demonstrated that the proposed model could find the best suppliers to procure, vehicles to transport, machines to assign to cells, and the priority of each part to process on the relevant machine, simultaneously. As an attained managerial insight, the sensitivity analysis of the proposed model showed when the delivery lead-time of candidate suppliers for the specific part increases, it may cause a reduction in mean waiting and inter-cell movement time for the same part. For future research, it is recommended to consider the capacity of vehicles, routes for a fleet of vehicles, and inventory models in order to become more realistic.

\section{References}

1. Chopra, S. and Meindl, P."Supply chain management. Strategy, planning \& operation", In Das summa summarum des management, Springer, Gabler, pp. 265-275 (2007).

2. Sadeghi, A. Suer, G. Sinaki, R.Y. et al. "Cellular manufacturing design and replenishment strategy in a capacitated supply chain system: A simulation-based analysis", Comput Ind Eng., 141, pp. 106-282 (2020).

3. Croom, S. Romano, P. and Giannakis, M. "Supply chain management: an analytical framework for critical literature review", J. Purch. Supply Manag, 6(1), pp. 67-83 (2000).

4. Tang, L. Jin, Z. Qin, X. et al. "Supply chain scheduling in a collaborative manufacturing mode: model construction and algorithm design", Ann. Oper. Res., 275(2), pp. 685-714 (2019).

5. Aminzadegan, S. Tamannaei, M. and Rasti-Barzoki, M. "Multi-agent supply chain scheduling problem by considering resource allocation and transportation", Comput Ind Eng., 137(1), pp. 106003 (2019).

6. Farzad, T. Mohammad Rasid, O. Aidy, A. et al. "A review of supplier selection methods in manufacturing industries", Suranaree J. Sci. Technol., 15(3), pp. 201-208 (2008).

7. Ho, W. Xu, X. and Dey, P.K. "Multi-criteria decision making approaches for supplier evaluation and selection: A literature review", Eur. J. Oper. Res., 202(1), pp. 16-24 (2010). 
8. Hammami, R. Frein, Y. and Hadj-Alouane, A.B. "An international supplier selection model with inventory and transportation management decisions", Flex. Serv. Manuf. J., 24(1), pp. 4-27 (2012).

9. Chai, J. Liu, J.N. and Ngai, E.W. "Application of decision-making techniques in supplier selection: A systematic review of literature", Expert Syst. Appl., 40(10), pp. 3872-3885 (2013).

10. Igarashi, M. de Boer, L. and Fet, A.M. "What is required for greener supplier selection? A literature review and conceptual model development", J. Purch. Supply Manag., 19(4), pp. 247263 (2013).

11. Pal, O. Gupta, A.K. and Garg, R. "Supplier selection criteria and methods in supply chains: A review", Int. J. Econ. Manag., 7(10), pp. 2667-2673 (2013).

12. Erozan, I. Torkul, O. and Ustun, O. "Proposal of a nonlinear multi-objective genetic algorithm using conic scalarization to the design of cellular manufacturing systems", Flex. Serv. Manuf. J., 27(1), pp. 30-57 (2015).

13. Wemmerlöv, U. and Hyer, N.L. "Cellular manufacturing in the US industry: a survey of users", Int. J. Prod. Res., 27(9), pp. 1511-1530 (1989).

14. Heragu, S.S. "Group technology and cellular manufacturing", IEEE Trans. Syst. Man Cybern. Syst., 24(2), pp. 203-215 (1994).

15. Shishebori, D. and Dehnavi-Arani, S. "A Multi-stage Stochastic Programming Approach in a Dynamic Cell Formation Problem with Uncertain Demand: A Case Study", Int J Supply Oper Manage, 6(1), pp. 67-87 (2019).

16. Rachamadugu, R. Nandkeolyar, U. and Schriber, T. "Scheduling with sequencing flexibility", Decis. Sci., 24(2), pp. 315-342 (1993).

17. Irani, S.A. "Handbook of cellular manufacturing systems", In John Wiley \& Sons (1999).

18. Wemmerlöv U. and Hyer, N.L. "Research issues in cellular manufacturing", Int. J. Prod. Res., 25(3), pp. 413-431 (1987).

19. Xue, G. and Offodile, O.F. "Integrated optimization of dynamic cell formation and hierarchical production planning problems", Comput Ind Eng., 139, p. 106155, (2020).

20. Kamrani, A.K. Parsaei, H.R. and Liles, D.H. "Planning, design, and analysis of cellular manufacturing systems", In Newnes (1995).

21. Wu, X. Chu, C.H. Wang, Y. et al. "Genetic algorithms for integrating cell formation with machine layout and scheduling", Comput Ind Eng., 53(2), pp. 277-289 (2007).

22. Lin, S.W. and Ying, K.C. "Makespan optimization in a no-wait flowline manufacturing cell with sequence-dependent family setup times", Comput Ind Eng., 128, pp. 1-7 (2019).

23. Wazed, M. Ahmed, S. and Nukman, Y. "Uncertainty factors in real manufacturing environment", Aust. J. Basic \& Appl. Sci., 3(2), pp. 342-351 (2009).

24. Kumar, R. and Singh, S.P. "Modified SA Algorithm for Bi-objective Robust Stochastic Cellular Facility Layout in Cellular Manufacturing Systems", In Advanced Computing and Communication Technologies, Springer, Singapore, pp. 19-33 (2019).

25. Hall, N.G. and Potts, C.N. "Supply chain scheduling: Batching and delivery", Oper. Res., 51(4), pp. 566-584 (2003).

26. Selvarajah, E. and Steiner, G. "Batch scheduling in a two-level supply chain-a focus on the supplier", Eur. J. Oper. Res., 173(1), pp. 226-240 (2006).

27. Wang, $X$. and Cheng, T.E. "Machine scheduling with an availability constraint and job delivery coordination", Nav. Res. Logist., 54(1), pp. 11-20 (2007).

28. Zegordi, S.H. and Nia, M.A.B. "Integrating production and transportation scheduling in a twostage supply chain considering order assignment", J. Adv. Manuf. Technol., 44(9), pp. 928-939 (2009). 
29. Yimer, A.D. and Demirli, K. "A genetic approach to two-phase optimization of dynamic supply chain scheduling", Comput Ind Eng., 58(3), pp. 411-422 (2010).

30. Zegordi, S.H. Abadi, I.K. and Nia, M.B. "A novel genetic algorithm for solving production and transportation scheduling in a two-stage supply chain", Comput Ind Eng., 58(3), pp. 373-381, (2010).

31. Steinrücke, M. "An approach to integrate production-transportation planning and scheduling in an aluminium supply chain network", Int. J. Prod. Res., 49(21), pp. 6559-6583 (2011).

32. Maheut, J. Garcia-Sabater, J.P. and Mula, J. "A supply chain operations lot-sizing and scheduling model with alternative operations", In Industrial Engineering: Innovative Networks, Springer, London, pp. 309-316 (2012).

33. Wang, D. Grunder, O. and El Moudni, A. "Single-item production-delivery scheduling problem with stage-dependent inventory costs and due-date considerations", Int. J. Prod. Res., 51(3), pp. 828-846 (2013).

34. Ma, H. Chan, F.T. and Chung, S. "Minimising earliness and tardiness by integrating production scheduling with shipping information", Int. J. Prod. Res., 51(8), pp. 2253-2267 (2013).

35. Hajiaghaei-Keshteli, M. Aminnayeri, M. and Ghomi, S.F. "Integrated scheduling of production and rail transportation", Comput Ind Eng., 74, pp. 240-256 (2014).

36. Cheng, B. Li, K. and Hu, X. "Approximation algorithms for two-stage supply chain scheduling of production and distribution", Int. J. Syst. Sci., 2(2), pp. 78-89 (2015).

37. Pei, J. Pardalos, P.M. Liu, X. et al. "Coordination of production and transportation in supply chain scheduling", J. Ind. Manag. Optim., 11(2), pp. 399-419 (2015).

38. Cheng, B.Y. Leung, J.Y.T. and Li, K. "Integrated scheduling of production and distribution to minimize total cost using an improved ant colony optimization method", Comput Ind Eng., 83, pp. 217-225 (2015).

39. Pei, J. Fan, W. Pardalos, P.M. et al. "Preemptive scheduling in a two-stage supply chain to minimize the makespan", Optim. Methods Softw., 30(3), pp. 727-747 (2015).

40. Assarzadegan, P. and Rasti-Barzoki, M. "Minimizing sum of the due date assignment costs, maximum tardiness and distribution costs in a supply chain scheduling problem", Appl. Soft Comput., 47, pp. 343-356 (2016).

41. Hassanzadeh, A. and Rasti-Barzoki, M. "Minimizing total resource consumption and total tardiness penalty in a resource allocation supply chain scheduling and vehicle routing problem", Appl. Soft Comput., 58, pp. 307-323 (2017).

42. Noroozi, A. Mazdeh, M.M. Noghondarian, K. et al. "Evolutionary computation algorithms to coordinating order acceptance and batch delivery for an integrated supply chain scheduling", Comput. Appl. Math, 37(2), pp. 1629-1679 (2018).

43. Wang, D. Zhu, J. Wei, X. et al. "Integrated production and multiple trips vehicle routing with time windows and uncertain travel times", Comput. Oper. Res., 103, pp. 1-12 (2019).

44. Arkat, J. Farahani, M.H. and Hosseini, L. "Integrating cell formation with cellular layout and operations scheduling", J. Adv. Manuf. Technol., 61(5-8), pp. 637-647 (2012).

45. Pasupuleti, V.C. "Scheduling in cellular manufacturing systems", Iberoam. J. Ind. Eng., 4(7), pp. 231-243 (2012).

46. Arkat, J. Farahani, M.H. and Ahmadizar, F. "Multi-objective genetic algorithm for cell formation problem considering cellular layout and operations scheduling", Int. J. Comput. Integr. Manuf., 25(7), pp. 625-635 (2012).

47. Kesen, S.E. and Güngör, Z. "Job scheduling in virtual manufacturing cells with lot-streaming strategy: a new mathematical model formulation and a genetic algorithm approach", J Oper Res Soc, 63(5), pp. 683-695 (2012). 
48. Eguia, I. Racero, J. Guerrero, F. et al. "Cell formation and scheduling of part families for reconfigurable cellular manufacturing systems using Tabu search", Simulation, 89(9), pp. 10561072 (2013).

49. Solimanpur, M. and Elmi, A. "A tabu search approach for cell scheduling problem with makespan criterion", Int. J. Prod. Econ., 141(2), pp. 639-645 (2013).

50. Taouji Hassanpour, S. Bashirzadeh, R. Adressi, A. et al. "Scheduling Problem of Virtual Cellular Manufacturing Systems (VCMS); Using Simulated Annealing and Genetic Algorithm based Heuristics", J. Mod Pro Manu Prod, 3(4), pp. 45-60 (2014).

51. Saravanan, M. and Karthikeyan, S. "Scheduling Optimization cell Formation Problem for Cellular Manufacturing System Using Meta-Heuristic Methods", Appl. Mech. Mater, 786, pp. 340-344 (2015).

52. Fahmy, S. A. "Mixed integer linear programming model for integrating cell formation, group layout and group scheduling", 2015 IEEE International Conference on Industrial Technology (ICIT), pp. 2403-2408 (2015).

53. Halat, K. and Bashirzadeh, R. "Concurrent scheduling of manufacturing cells considering sequence-dependent family setup times and intercellular transportation times", J. Adv. Manuf. Technol., 77(9), pp. 1907-1915 (2015).

54. Liu, C. and Wang, J. "Cell formation and task scheduling considering multi-functional resource and part movement using hybrid simulated annealing", Int. J. Comput. Intell. Syst., 9(4), pp. 765777 (2016).

55. Egilmez, G. Mese, E.M. Erenay, B. et al. "Group scheduling in a cellular manufacturing shop to minimise total tardiness and $\mathrm{nT}$ : a comparative genetic algorithm and mathematical modelling approach", Int J Serv Oper Manag, 24(1), pp. 125-146 (2016).

56. Rafiei, H. Rabbani, M. Gholizadeh, H. et al. "A novel hybrid SA/GA algorithm for solving an integrated cell formation-job scheduling problem with sequence-dependent set-up times", Int. J. Manag. Sci, 11(3), pp. 134-142, 2016.

57. Liu, C. Wang, J. Leung, J.Y.T. et al. "Solving cell formation and task scheduling in cellular manufacturing system by discrete bacteria foraging algorithm", Int. J. Prod. Res., 54(3), pp. 923944 (2016).

58. Deliktas, D. Torkul, O. and Ustun, O. "A flexible job shop cell scheduling with sequencedependent family setup times and intercellular transportation times using conic scalarization method", Int. Trans. Oper. Res., 26(6), pp. 2410-2431 (2017).

59. Feng, Y. Li, G. and Sethi, S.P. "A three-layer chromosome genetic algorithm for multi-cell scheduling with flexible routes and machine sharing", Int. J. Prod. Econ., 196, pp. 269-283 (2018).

60. Feng, H. Xia, T. Da, W. et al. "Concurrent design of cell formation and scheduling with consideration of duplicate machines and alternative process routings", J. Intell. Manuf., 30(1), pp. 275-289 (2019).

61. Forghani, K. and Ghomi, S.F. "Joint cell formation, cell scheduling, and group layout problem in virtual and classical cellular manufacturing systems", Appl. Soft Comput., 97, p. 106719 (2020).

62. Ramezanian, R. and Khalesi, S. "Integration of multi-product supply chain network design and assembly line balancing", Oper. Res., pp. 1-31 (2019).

63. Mallor, F. Azcárate, C. and Barado, J. "Control problems and management policies in health systems: application to intensive care units", Flex. Serv. Manuf. J., 28(1-2), pp. 62-89 (2016).

64. Simchi-Levi, D. Kaminsky, P. and Simchi-Levi, E. "Managing the Supply Chain: Definitive Guide", In Tata McGraw-Hill Education (2004).

65. Donald, G. and Carl, H. "Fundamentals of queueing theory", In John Wiley \& Sons, Hoboken, New Jersey (2008). 
66. Ballakur, A. "An investigation of part family/machine group formation in designing a cellular manufacturing system", Ph. D. Thesis, University of Wisconsin (1985).

67. King, J.R. and Nakornchai, V. "Machine-component group formation in group technology: review and extension", Int. J. Prod. Res., 20(2), pp. 117-133 (1982).

68. Hazarika, M. and Laha, D. "A heuristic approach for Machine Cell Formation problems with Alternative Routings", Procedia Comput. Sci., 89, pp. 228-242 (2016).

\section{Biographies}

Bahman Esmailnezhad received his BSc degree in Industrial Engineering from University of Tabriz in 2011, Tabriz, Iran, and his MSc degree in Industrial Engineering from Bu-Ali University in 2013, Hamedan, Iran. He is currently a PhD student in the same major in Iran University of Science and Technology, Tehran, Iran. His research interests include supply chain network design, cellular manufacturing, maintenance, queuing theory, and meta-heuristic algorithms. He has published 7 papers in related fields in some journals, and 5 papers in some international conferences.

Mohammad Saidi-Mehrabad is a professor of department of Industrial Engineering at Iran University of Science and Technology. He has received his BSc degree in Mechanical Engineering from Oklahoma State University in 1983 and his MSc and PhD degrees in Industrial Engineering from University of Arkansas and West Virginia University in 1992. His major research interests are in cellular manufacturing and supply chain and production planning, and every optimization problem. He has published some books and a large number of papers in high impact international journals and many papers in research indexed journals and international conferences.

\section{Figures}

Figure 1: Illustration of the proposed problem

Figure 2: Queuing system for the first step

Figure 3: Queuing system for the second step

Figure 4: Queuing system for the third step

Figure 5: The GA framework.

Figure 6: A sample solution representation

Figure 7: Steps for generating initial population

Figure 8: The offspring resulted from crossover between parent 1 and parent 2

Figure 9: The mutated solution resulted from applying mutation

Figure 10: The comparison the performance of the GA and the B\&B of Lingo software

Figure 11: The convergence of the GA for test problem 5

Figure 12: Detailed solution of the case study 
Figure 13: the behavior of inter-cell movement, mean waiting time, and the sum of both with varying the delivery lead-time of candidate suppliers for part 4

\section{Tables}

Table 1: The summary of literature and comparison with this research

Table 2: The candidates and obtained values for the GA parameters

Table 3: The results of the B\&B of Lingo software and the GA

Table 4: The assigned machines to cells

Table 5: Detailed data of candidate suppliers, demand rate, and due date

Table 6: the mean service rate of machines

Table 7: The mean service rate of vehicles to transport raw materials from suppliers

\section{Figures}




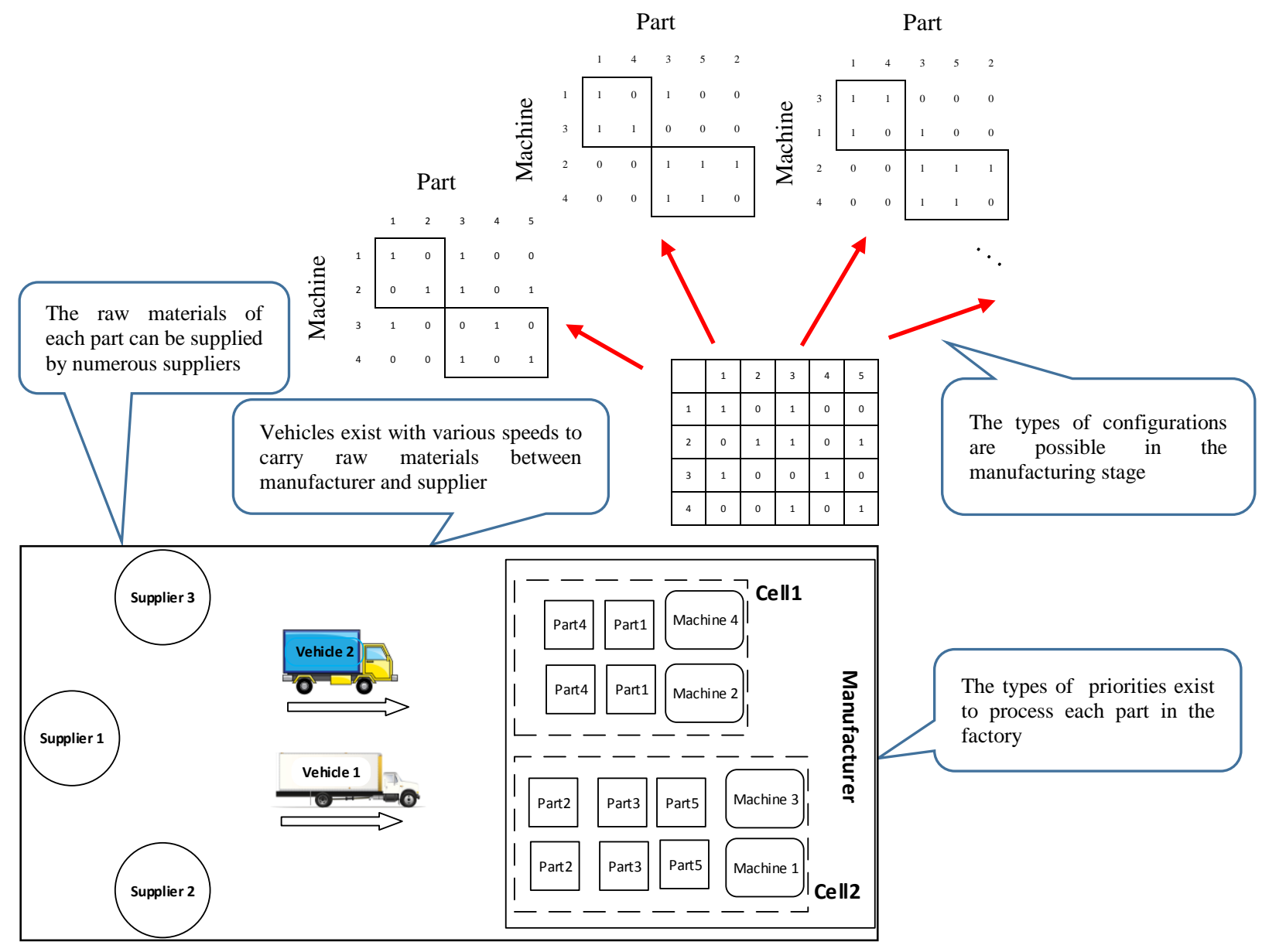

Figure 14

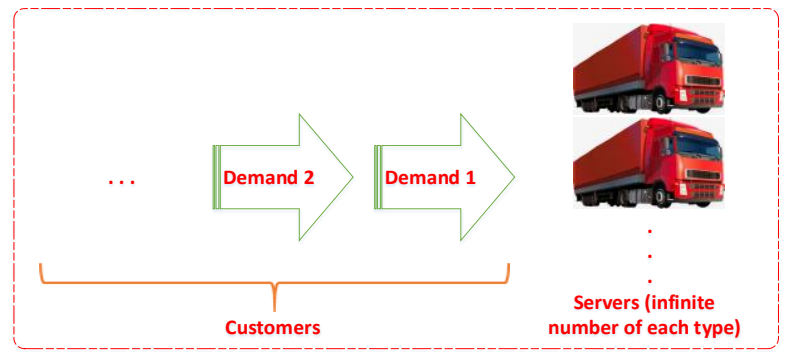

Figure 15

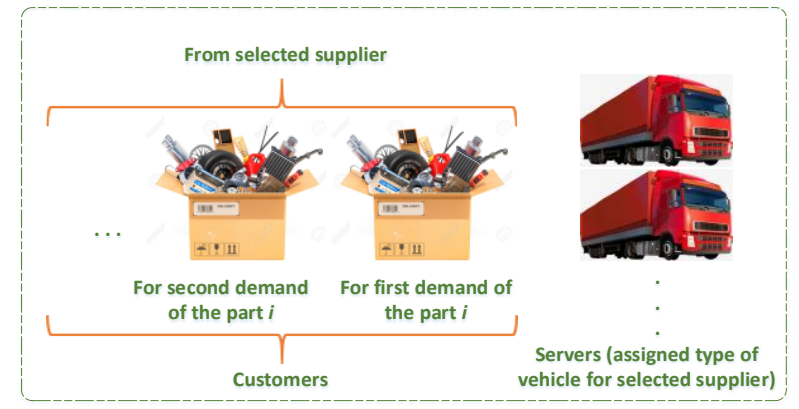

Figure 16 


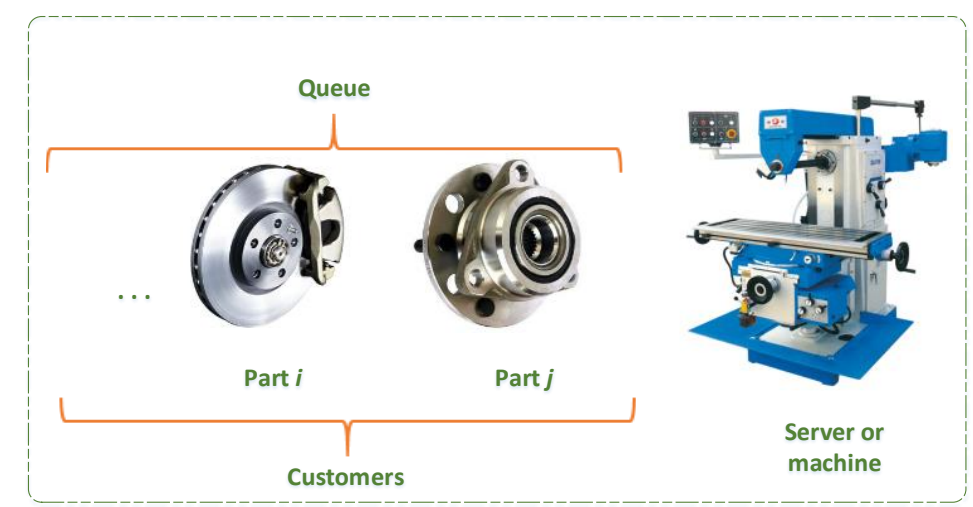

Figure 17

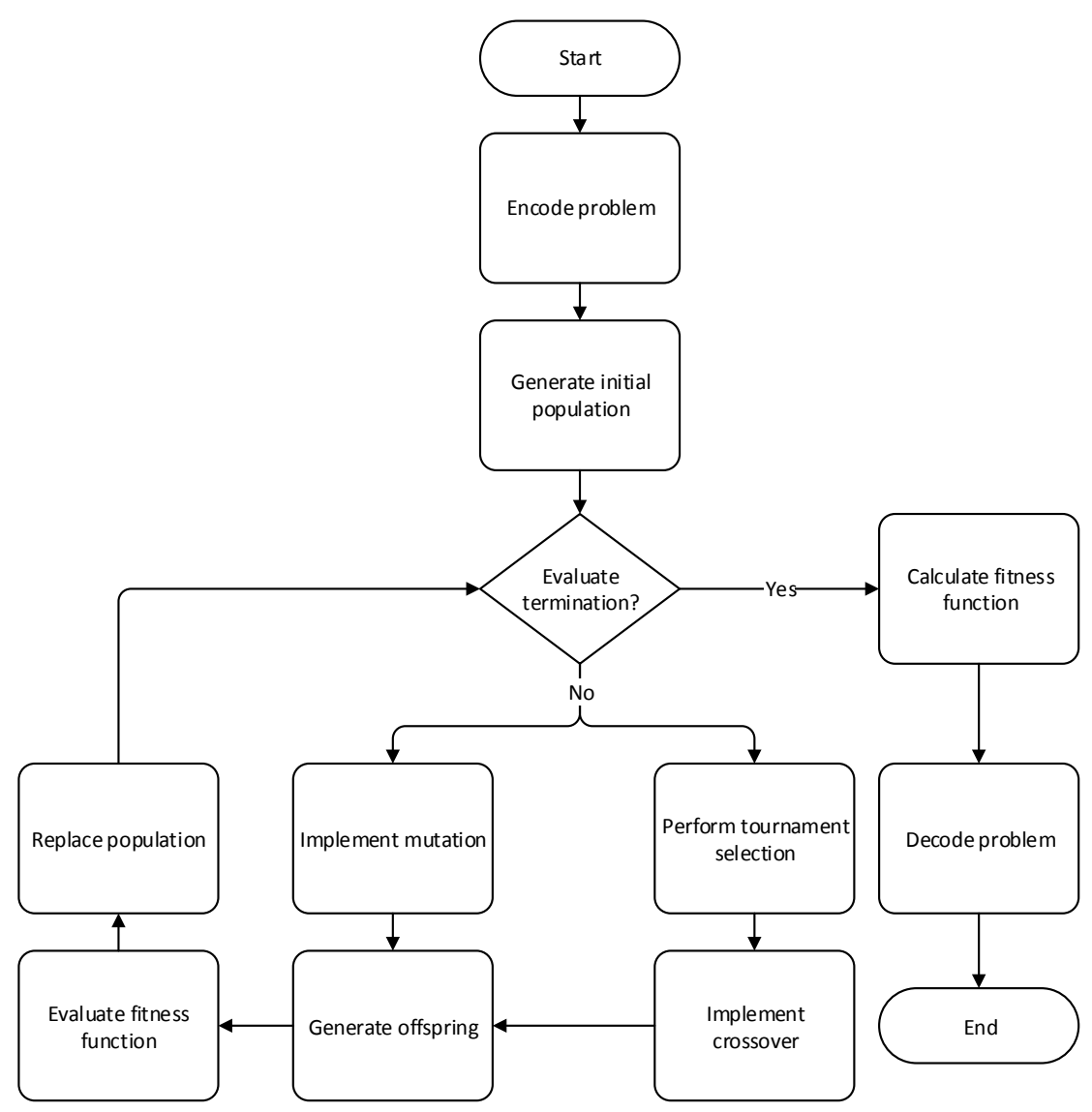

Figure 18

\begin{tabular}{|c|c|c|c|c|c|c|c|c|c|c|c|c|}
\hline \multicolumn{3}{|c|}{$\mathrm{P}$} & \multicolumn{3}{|c|}{$\mathrm{P}$} & \multicolumn{4}{|c|}{$\mathrm{M}$} & \multicolumn{3}{|c|}{$\mathrm{P}$} \\
\hline 1 & 2 & 3 & 1 & 2 & 3 & 1 & 2 & 3 & 4 & 1 & 2 & 3 \\
\hline 3 & 1 & 2 & 2 & 1 & 3 & 1 & 1 & 2 & 2 & 2 & 3 & 1 \\
\hline
\end{tabular}

Assigned vehicle Selected supplier $\quad$ Assigned cell Part priority

Figure 19 
Step 1: Set $r=1$ (population index) and identify population of chromosomes $\rightarrow$ pop ;

Step 2: Set $i=1$ (index for the array number in the chromosome) $0<i \leq 3 \times P+M$;

Step 3: If " $i \leq P$ ";

3-1: Generate a random integer between 1 to $V \rightarrow X(i)\left(X\right.$ is the chromosome and $X(i)$ is $i^{\text {th }}$ position of the matrix or the chromosome) and go to sub-step 3-2;

3-2: $i \leftarrow i+1$ and go back to step 3;

Else go to step 4 ;

Step 4: If " $i \leq 2 \times P$ ";

4-1: Select randomly among suppliers with production capability of raw materials for the respective part $\rightarrow X(i)$, and go to sub-step 4-2;

4-2: $i \leftarrow i+1$ and go back to step 4;

Else go to step 5;

Step 5: Set the number of machines inside eachcell $=0$ and go to step 6;

Step 6: If " $i \leq 2 \times P+M$ ";

6-1:Generate a random integer between 1 to $C \rightarrow d$, and go to sub-step 6-2;

6-2: If "the number of assigned machines to cell $d \leq M_{\max }$ ";

6-2-1: (The number of machines inside the cell $d)+1 \rightarrow($ the number of machines inside the cell $d$ ) and $X(i) \leftarrow d$. Then, go to sub-step 6-4;

6-3: Else $i=2 \times P+1$, set the number of machines inside each cell $=0$. Then, go back to step 6;

6-4: $i \leftarrow i+1$ and go back to step 6;

Else, go to step 7;

Step 7: Generate randomly a permutation with $P$ elements and fill positions from $X(i)$ to $X(i+P)$.

Go to step 8;

Step 8: If " $p o p<r$ ";

8-1: $r \leftarrow r+1$ and go back step 2 ;

Else, "End";

Figure 20 
Parent 1

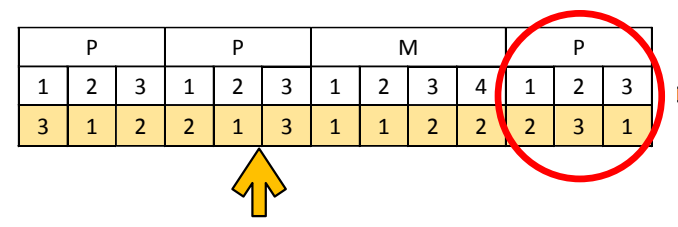

Parent 2

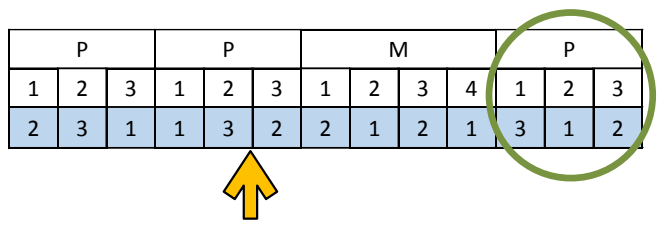

Child 1
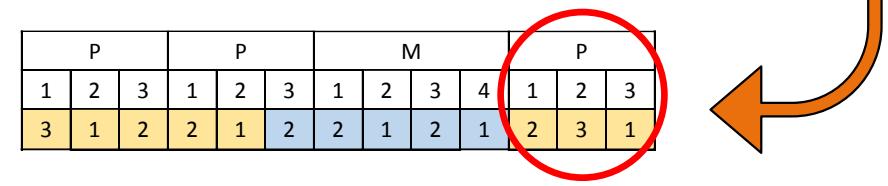

Child 2
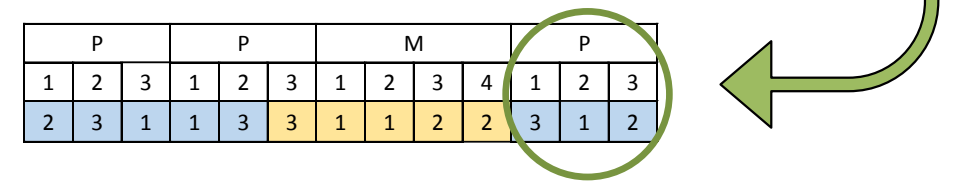

Figure 21

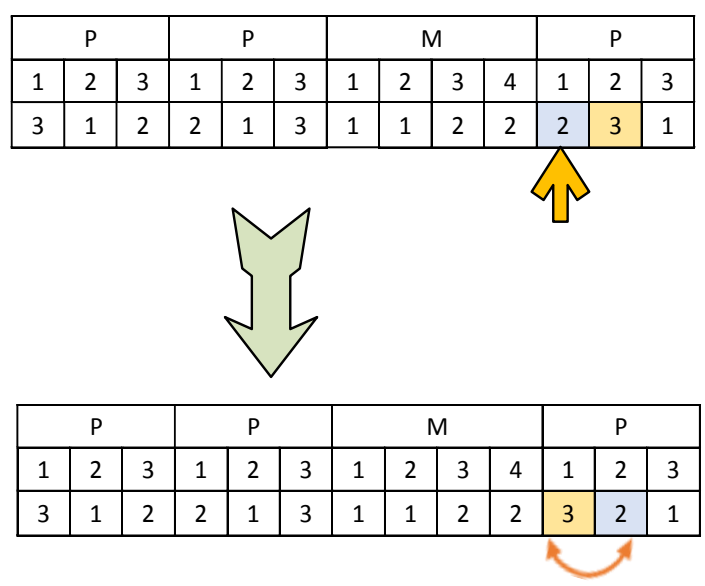

Figure 22 


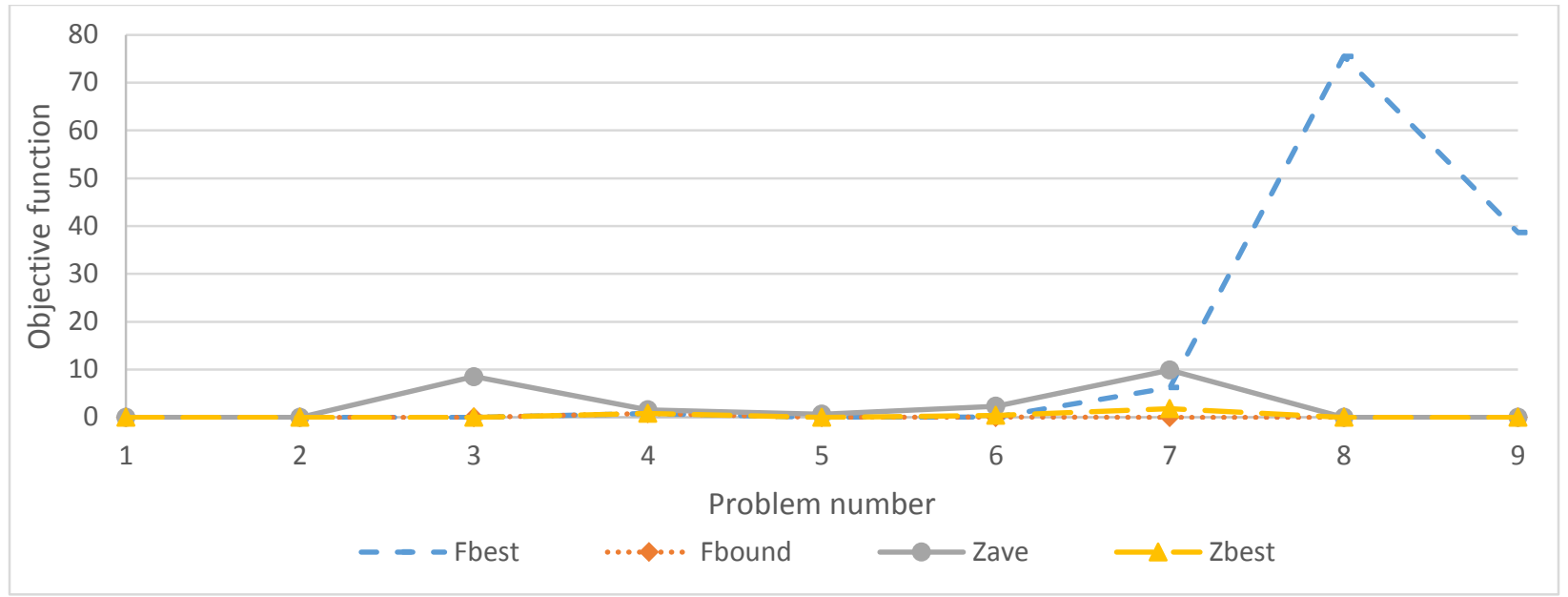

Figure 23

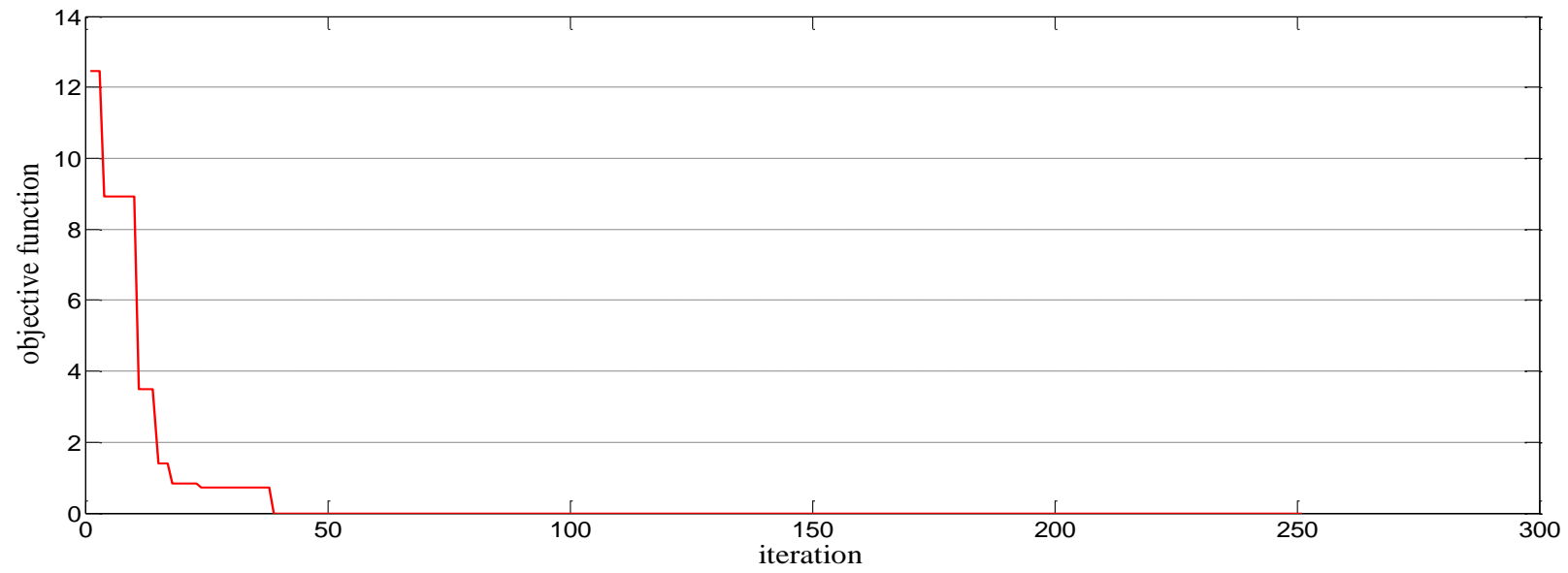

Figure 24 


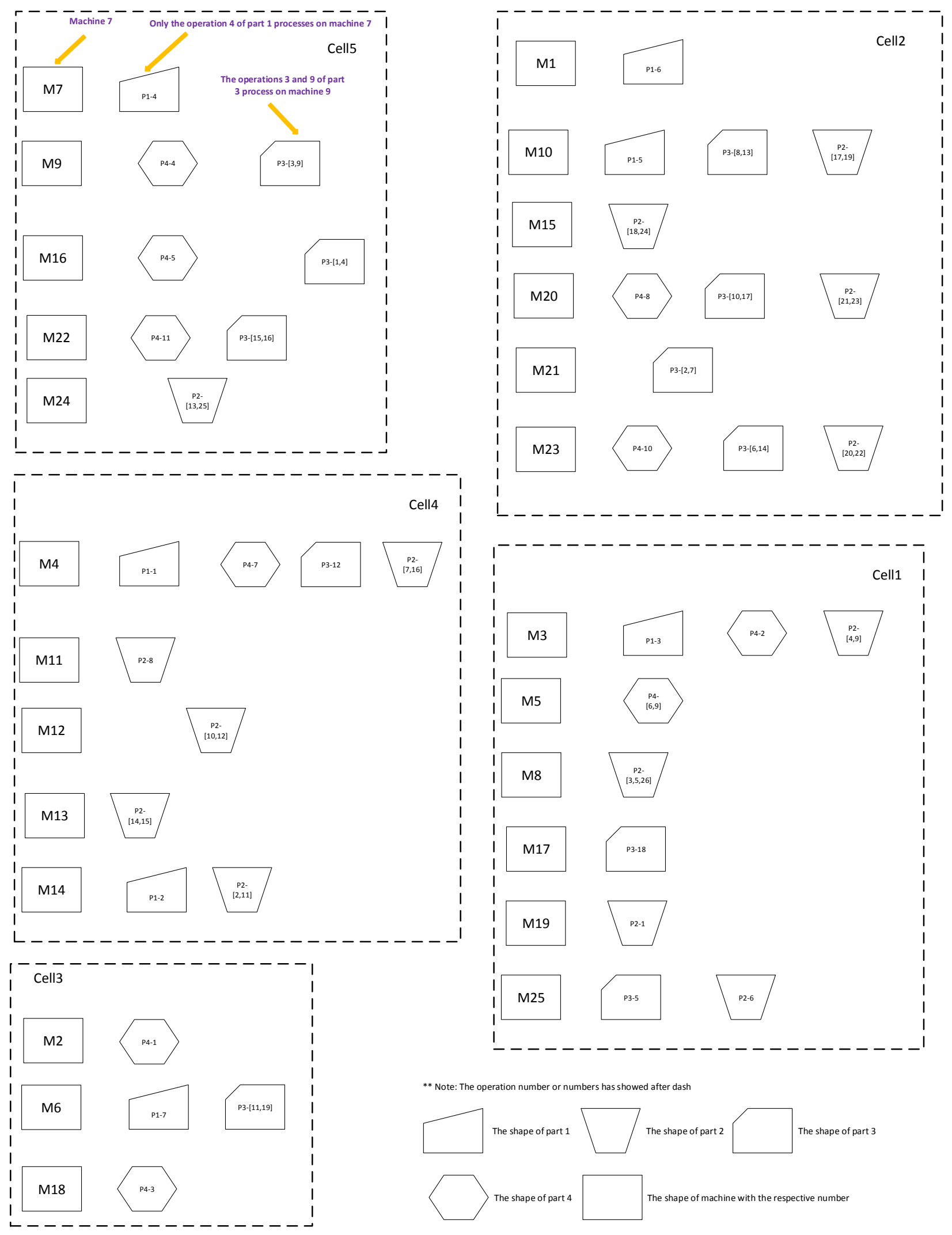

Figure 25 


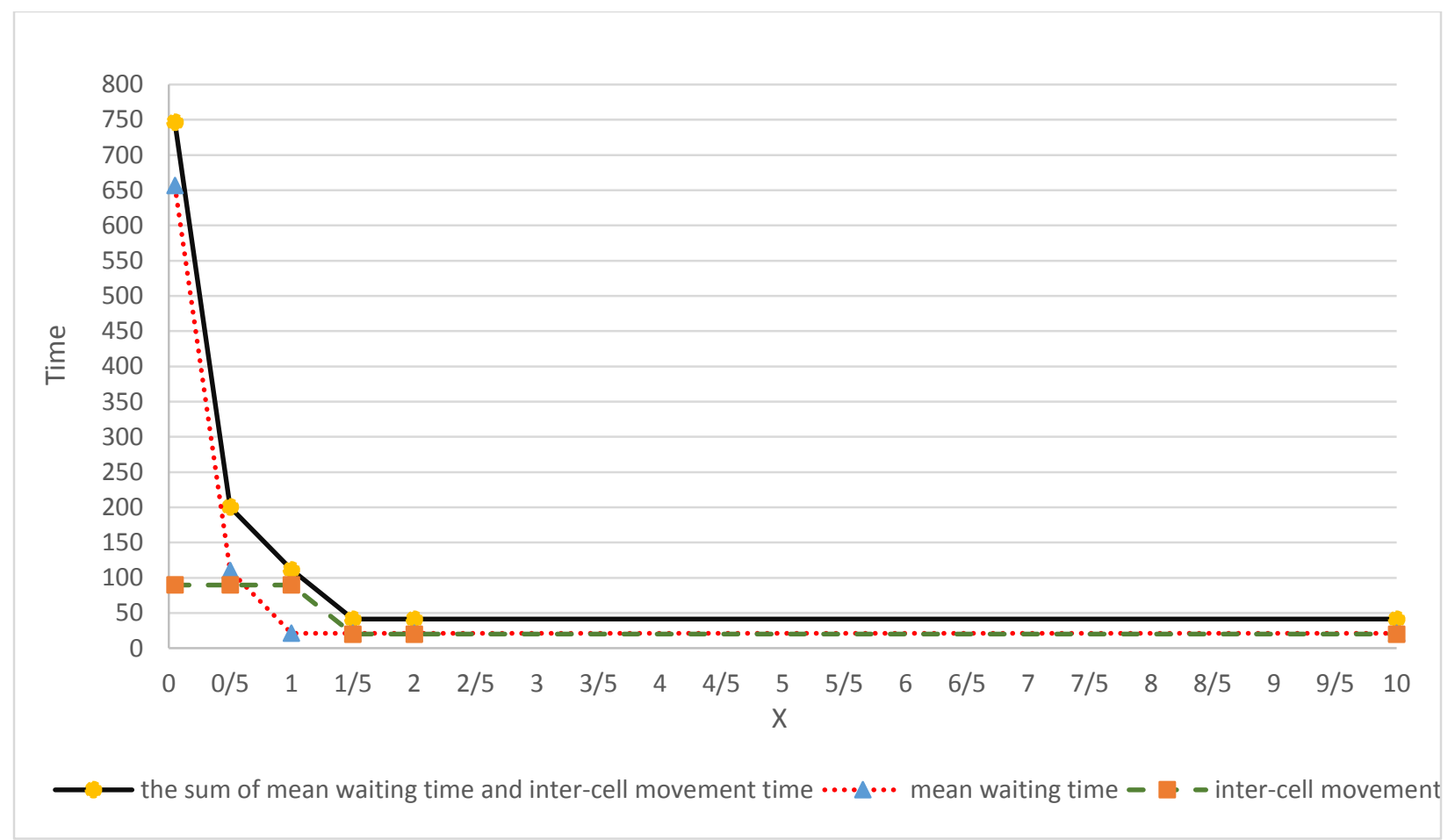

Figure 26

Tables 
Table 8

\begin{tabular}{|c|c|c|c|c|c|c|c|c|}
\hline & No. & authors & Year & $\begin{array}{l}\text { Supply chain } \\
\text { stages }\end{array}$ & $\begin{array}{l}\text { Scheduled } \\
\text { component }\end{array}$ & $\begin{array}{c}\text { Uncertain } \\
\text { component }\end{array}$ & Objective function & Solving method \\
\hline \multirow{21}{*}{ 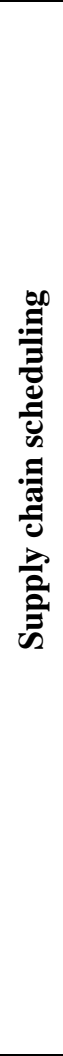 } & 1 & Hall \& Potts & 2003 & $\begin{array}{c}S \& M-S, M \\
\& C\end{array}$ & $\mathrm{~S} \& \mathrm{M}$ & & 1-Min TCT 2-Min $\mathrm{L}_{\max }$ 3-Min NLJ & $\mathrm{H}$ \\
\hline & 2 & Selvarajah \& Steiner & 2006 & $\mathrm{M} \& \mathrm{C}$ & M & & Min C(INV+TTD) & $\mathrm{H}$ \\
\hline & 3 & Wang \& Cheng & 2007 & $M \& C$ & M & & $\operatorname{Min} \mathrm{C}_{\max }$ & $\mathrm{H}$ \\
\hline & 4 & Zegordi \& Nia & 2009 & S \& M & $\mathrm{M} \& \mathrm{~T}$ & & $\operatorname{Min} \mathrm{C}_{\max }$ & DGA \\
\hline & 5 & Yimer \& Demirli & 2010 & M \& W & $\mathrm{M} \& \mathrm{~T}$ & & $\begin{array}{c}\text { 1-Min } \mathrm{C}(\mathrm{OP}+\mathrm{DC}+\mathrm{TTD}) \text { 2-Min } \\
\mathrm{C}(\mathrm{FI}+\mathrm{OP})\end{array}$ & GA \& MM \\
\hline & 6 & Zegordi et al & 2010 & S \& M & $\mathrm{T}$ & & Min $\mathrm{C}_{\max }$ & GGA \\
\hline & 7 & Steinrücke & 2011 & S, M \& C & $\mathrm{M} \& \mathrm{~T}$ & & Min C(OP+TTD+DE) & RFH \\
\hline & 8 & Maheut et al. & 2012 & $\mathrm{~S}, \mathrm{M} \& \mathrm{C}$ & $\mathrm{M}$ & & Min C(INV+OP+FI) & - \\
\hline & 9 & Wang et al. & 2013 & $\mathrm{M}, \mathrm{W} \& \mathrm{C}$ & $\mathrm{M} \& \mathrm{~T}$ & & Min $\mathrm{C}(\mathrm{OP}+\mathrm{TTD}+\mathrm{INV})$ & - \\
\hline & 10 & Ma et al. & 2013 & $M \& W$ & $\mathrm{M} \& \mathrm{~T}$ & & Min C(WS+TTD+DC+TT) & TLGA \\
\hline & 11 & Hajiaghaei-Keshteli et al. & 2014 & $\mathrm{M} \& \mathrm{C}$ & M & & Min C(DE+TT+TTD) & GA, SA,H \&MM \\
\hline & 12 & Cheng et al. & 2015 & M \& W & $\mathrm{M} \& \mathrm{~T}$ & & Min TI(OP+TTD) & $\mathrm{H}$ \\
\hline & 13 & Pei et al. & 2015 & S \& M & S \& M & & Min $\mathrm{C}_{\max }$ & $\mathrm{H}$ \\
\hline & 14 & Cheng et al. & 2015 & $\mathrm{M} \& \mathrm{C}$ & $\mathrm{M}$ & & Min C(OP+TTD) & $\mathrm{H}(\mathrm{ACO} / \mathrm{H})$ \\
\hline & 15 & Pei et al. & 2015 & $\mathrm{M} \& \mathrm{C}$ & $\mathrm{M} \& \mathrm{~T}$ & & Min $\mathrm{C}_{\max }$ & $\mathrm{H}$ \\
\hline & 16 & $\begin{array}{c}\text { Assarzadegan \& Rasti- } \\
\text { Barzoki }\end{array}$ & 2016 & $M \& C$ & $M \& \mathrm{~T}$ & & $\operatorname{Min} C\left(\mathrm{~T}_{\max }+\mathrm{DA}+\mathrm{TTD}\right)$ & AGA \& PSA \\
\hline & 17 & $\begin{array}{c}\text { Hassanzadeh \& Rasti- } \\
\text { Barzoki }\end{array}$ & 2017 & $\mathrm{M} \& \mathrm{C}$ & $\mathrm{M} \& \mathrm{~T}$ & & 1-Min C(TT) 2-Min C(OP+TTD) & VNSGA-II \& NSGA-II \\
\hline & 18 & Noroozi et al. & 2018 & $\mathrm{M} \& \mathrm{C}$ & $M \& T$ & & Max RO-C(TT+TTD) & $\mathrm{H}(\mathrm{PSO} / \mathrm{GA})$ \\
\hline & 19 & Wang et al. & 2019 & $\mathrm{M} \& \mathrm{C}$ & $\mathrm{M} \& \mathrm{~T}$ & $\mathrm{~T}$ & Min C(TTD+TT) & MA \\
\hline & 20 & Tang et al. & 2019 & $\mathrm{M} \& \mathrm{C}$ & M & & Min $\mathrm{C}(\mathrm{INV}+\mathrm{OP}+\mathrm{TJ}+\mathrm{DE})$ & $\begin{array}{c}\mathrm{HACO}, \mathrm{GA}, \mathrm{ACO} \& \mathrm{IM}- \\
\mathrm{ACO}\end{array}$ \\
\hline & 21 & Aminzadegan et al. & 2019 & $\mathrm{M} \& \mathrm{C}$ & M & & Min C(RA+TT+BD+ TNTO) & MM, AGA, ALO \& H \\
\hline
\end{tabular}


Table 1 (continued)

\begin{tabular}{|c|c|c|c|c|c|c|c|c|}
\hline \multirow{19}{*}{ 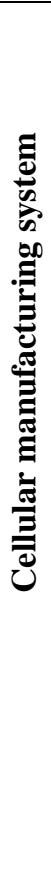 } & 22 & Arkat et al. & 2012 & M & $\mathrm{M}$ & & \multirow{2}{*}{$\begin{array}{c}\text { 1-Min C(Intr+Inte)2-Min TCT } \\
\text { 1-Min } \mathrm{C}_{\max } \text { 2-Min M(FT) 3-Min } \\
\text { M(LA) 4-Min M(TJ) }\end{array}$} & \multirow{2}{*}{$\begin{array}{c}\text { GA \& MM } \\
\text { H }\end{array}$} \\
\hline & 23 & Pasupuleti & 2012 & M & $\mathrm{M}$ & & & \\
\hline & 24 & Arkat et al. & 2012 & M & M & & 1-Min C(Intr+Inte)2-Min $\mathrm{C}_{\max }$ & PGA \\
\hline & 25 & Kesen and Gungor & 2012 & M & M & & $\operatorname{Min} \mathrm{C}_{\max }$ & GA \\
\hline & 26 & Eguia et al. & 2013 & M & $\mathrm{M}$ & & Min $\mathrm{C}(\mathrm{OP})$ & TS \\
\hline & 27 & Solimanpur and Elmi & 2013 & M & M & & $\operatorname{Min} \mathrm{C}_{\max }$ & NTS \\
\hline & 28 & Taouji Hassanpour et al. & 2014 & M & M & & Min W(TT+Intr+Inte) & SA, GA \& MM \\
\hline & 29 & $\begin{array}{l}\text { Saravanan and } \\
\text { Karthikeyan }\end{array}$ & 2015 & M & $\mathrm{M}$ & & Min C(TT) & PSO \& GA \\
\hline & 30 & Fahmy & 2015 & M & M & & Min $\mathrm{M}(\mathrm{FT})$ & MM \\
\hline & 31 & Halat and Bashirzadeh & 2015 & M & $\mathrm{M}$ & & Min $\mathrm{C}_{\max }$ & GA \& MM \\
\hline & 32 & Liu and Wang & 2016 & & & & Min $C_{\max }$ & $\mathrm{H}(\mathrm{SA})$ \\
\hline & 33 & Egilmez et al. & 2016 & M & M & & 1-Min TT 2-Min NTJ & MM \& GA \\
\hline & 34 & Rafiei et al. & 2016 & M & M & & Min $\mathrm{C}(\mathrm{OP}+$ Inte+ Intr) & $\mathrm{H}(\mathrm{SA} / \mathrm{GA}) \& \mathrm{MM}$ \\
\hline & 35 & Liu et al. & 2016 & M & M & & Min C(Inte+FI+OP) & DBFA \\
\hline & 36 & Deliktas et al. & 2017 & M & M & & $\operatorname{Min} \mathrm{C}_{\max }$ & MM \\
\hline & 37 & Feng et al. & 2018 & M & M & & 1- Min $\mathrm{C}_{\max } 2-\mathrm{Min} \mathrm{TW}$ & TCGA, MM \& GA \\
\hline & 38 & Feng et al. & 2019 & M & M & & Min TCT & IGA \& MM \\
\hline & 39 & $\begin{array}{c}\text { Forghani and Fatemi } \\
\text { Ghomi }\end{array}$ & 2020 & M & $\mathrm{M}$ & & $\operatorname{Min} \mathrm{W}(\mathrm{C}(\mathrm{TTD})+\mathrm{M}(\mathrm{CT}))$ & MM, GA, SA \& MA \\
\hline & & This research & & $\mathrm{S} \& \mathrm{M}$ & M & $\mathrm{T} \& \mathrm{M}$ & Min TCT & GA \& MM \\
\hline
\end{tabular}

**Notes: Dash (-) means two types of a problem were investigated and stages are named based on [1]. Supplier: S, Manufacturer: M, Customer: C, Transportation: $\mathrm{T}$, and Warehouse or Distributer: W

Objectives are numbered in multi objective models and independent models individually. Functions were used in the objectives are named such as; The weighed function: W(), The time function: $\mathrm{TI}()$, The cost function: $\mathrm{C}()$, and The mean function: $\mathrm{M}()$. Moreover, terms in the objectives named such as; makespan: $\mathrm{C}_{\text {max }}$, total workload: TW, intercellular movement: Inte, intracellular movement: Intr, fixed costs: C(FI), costs of operations: C(OP), total tardiness: TT, the number of tardy jobs: NTJ, flow time: FT, tardiness of each job: TJ, total travelling distance: TTD, mean lateness: M(LA), the total completion time: TCT, revenue of orders: RO, maximum tardiness: $\mathrm{T}_{\max }$, Due date assignment cost per extended time: $\mathrm{C}(\mathrm{DA})$, delivery earliness cost: $\mathrm{C}(\mathrm{DE})$, warehouse storage cost: $\mathrm{C}(\mathrm{WS})$, distribution center storage cost: $\mathrm{C}(\mathrm{DC})$, inventory cost: $\mathrm{C}(\mathrm{INV})$, maximum lateness: $\mathrm{L}_{\max }$, number of late jobs: NLJ, resource allocation cost: $\mathrm{C}(\mathrm{RA})$, batch delivery cost: $\mathrm{C}(\mathrm{BD})$, the total number of tardy orders cost: $\mathrm{C}(\mathrm{TNTO})$, cycle time: $\mathrm{CT}$

A hybrid algorithm is shown as $\mathrm{H}()$ which algorithms are put on the inside of parenthesizes. Solving method are named such as; mathematical modelling: MM, genetic algorithm: GA, three-layer chromosome genetic algorithm: TCGA, discrete bacteria foraging algorithm: DBFA, simulated annealing: SA, Particle Swarm 
Optimization: PSO, Tabu search algorithm: TS, nested tabu search algorithm: NTS, proposed genetic algorithm: PGA, heuristic: H, memetic algorithm: MA, Non-dominated Sorting Genetic Algorithm II: NSGA-II, Variable Neighborhood Search based Non-dominated Sorting Genetic Algorithm II: VNSGA-II, Adaptive Genetic Algorithm: AGA, Parallel Simulated Annealing algorithm: PSA, ant colony optimization method: ACO, two-level genetic algorithm: TLGA, relax-and fix heuristics: RFH, gendered genetic algorithm: GGA, dynamic genetic algorithm: DGA, improved ant colony algorithm: IM-ACO, Ant Lion Optimization: ALO, improved genetic algorithm: IGA 
Table 9

\begin{tabular}{c|cccccc}
\hline & \multicolumn{6}{c}{ Problem scale } \\
\cline { 2 - 7 } Factor & candidates & obtained & $\begin{array}{c}\text { medium } \\
\text { candidates }\end{array}$ & obtained & large \\
candidates & obtained \\
\hline $\begin{array}{c}\text { Maximum } \\
\text { Iteration } \\
\text { Population } \\
\text { Size }\end{array}$ & $\{40,50,60,70\}$ & 40 & $\{200,250,300,350\}$ & 250 & $\{300,350,400,450\}$ & 300 \\
$\begin{array}{c}\text { Mutation } \\
\text { Probability }\end{array}$ & $\{0.2,0.3,0.4,0.5\}$ & 0.2 & $\{0.3,0.4,0.5,0.6\}$ & 0.5 & $\{0.3,0.4,0.5,0.6\}$ & 0.3 \\
$\begin{array}{c}\text { Tournament } \\
\text { Size }\end{array}$ & $\{2,3\}$ & 2 & $\{2,3\}$ & 2 & $\{2,3\}$ & 2 \\
$\begin{array}{c}\text { Crossover } \\
\text { Probability }\end{array}$ & $\{0.2,0.3,0.4,0.5\}$ & 0.3 & $\{0.4,0.5,0.6,0.7\}$ & 0.6 & $\{0.2,0.3,0.4,0.5\}$ & 0.2 \\
\hline
\end{tabular}

Table 10

\begin{tabular}{|c|c|c|c|c|c|c|c|c|c|c|c|c|c|}
\hline \multirow[b]{2}{*}{$\begin{array}{c}\text { Problem } \\
\text { No. }\end{array}$} & \multirow[b]{2}{*}{$P$} & \multirow[b]{2}{*}{$M$} & \multirow[b]{2}{*}{ C } & \multirow[b]{2}{*}{ Mmax } & \multirow[b]{2}{*}{ V } & \multirow[b]{2}{*}{$S$} & \multicolumn{3}{|c|}{$B \& B$} & \multicolumn{4}{|c|}{$\mathrm{GA}$} \\
\hline & & & & & & & Fbest & Fbound & $\mathrm{TB} \& \mathrm{~B}(\mathrm{~s})$ & Zave & Zbest & SD & TGA(s) \\
\hline 1 & 4 & 3 & 2 & 2 & 3 & 12 & 0 & 0 & 6 & 0 & 0 & 0 & 0 \\
\hline 2 & 4 & 4 & 2 & 3 & 3 & 12 & 0 & 0 & 11 & 0 & 0 & 0 & 0 \\
\hline 3 & 5 & 5 & 2 & 3 & 7 & 15 & 0 & 0 & 112 & 8.51 & 0 & 7.1 & 0 \\
\hline 4 & 5 & 11 & 3 & 4 & 5 & 15 & 0.8267 & 0.8267 & 1471 & 2 & 0.8267 & 1.1 & 78 \\
\hline 5 & 5 & 12 & 4 & 4 & 8 & 15 & 0.0 & 0.0 & 1556 & 0.7 & 0.0 & 0.9 & 112 \\
\hline 6 & 5 & 14 & 2 & 7 & 5 & 15 & 0.0602 & 0.0602 & 3433 & 2.3 & 0.4156 & 1.8 & 70 \\
\hline 7 & 5 & 20 & 5 & 5 & 7 & 15 & 6.2 & 0.0 & 5400 & 9.9 & 1.8132 & 5.8 & 185 \\
\hline 8 & 5 & 23 & 6 & 4 & 6 & 15 & 75.5 & 0.0 & 5400 & 0.0 & 0.0 & 0.0 & 40 \\
\hline 9 & 5 & 25 & 7 & 4 & 8 & 15 & 38.6673 & 0 & 5400 & 0.0 & 0 & 0.0 & 60 \\
\hline
\end{tabular}

Table 11

\begin{tabular}{cccccc}
\hline \multirow{2}{*}{ Machines } & Cell 1 & Cell 2 & Cell 3 & Cell 4 & Cell 5 \\
\cline { 2 - 6 } & $\{3,5,8,17,19,25\}$ & $\{1,10,15,20,21,23\}$ & $\{2,6,18\}$ & $\{4,11,12,13,14\}$ & $\{7,9,16,22,24\}$ \\
\hline
\end{tabular}


Table 12

\begin{tabular}{ccccc}
\hline & Part1 & Part2 & Part3 & Part4 \\
\cline { 2 - 5 } $\begin{array}{c}\text { Candidate } \\
\text { suppliers } \\
\begin{array}{c}\text { (delivery } \\
\text { lead-time) }\end{array}\end{array}$ & $\{1(720), 5(1440)\}$ & $\{3(4320), 7(2160)\}$ & $\{2(2880), 6(3600)\}$ & $\{4(3600), 8(720)\}$ \\
$\begin{array}{c}\text { Demand rate } \\
\text { Due date }\end{array}$ & 0.5900 & 0.5580 & 0.3090 & 0.4050 \\
\hline
\end{tabular}

Table 13

\begin{tabular}{ccccc}
\hline & Part1 & Part2 & Part3 & Part4 \\
\cline { 2 - 5 } Machine1 & 17.1429 & - & - & - \\
Machine2 & - & - & - & 0.5746 \\
Machine3 & 5.9406 & 2.1429 & - & 2.1201 \\
Machine4 & 2.9126 & 4.5872 & 1.7143 & 3.0769 \\
Machine5 & - & - & - & 1.7746 \\
Machine6 & 4.3796 & - & 1.0782 & - \\
Machine7 & 3.2432 & - & - & - \\
Machine8 & - & 2.2447 & - & - \\
Machine9 & - & - & 0.9091 & 1.994 \\
Machine10 & 6 & 4.5872 & 1.7143 & 5.4545 \\
Machine11 & - & 2.5641 & - & - \\
Machine12 & - & 4.4346 & - & - \\
Machine13 & - & 1.1669 & - & - \\
Machine14 & 3.352 & 1.9868 & - & - \\
Machine15 & - & 1.4061 & - & - \\
Machine16 & - & - & 1.1719 & 1.7411 \\
Machine17 & - & - & 3.5294 & - \\
Machine18 & - & - & - & 4.2857 \\
Machine19 & - & 5.2678 & - & - \\
Machine20 & - & 4.5872 & 1.8182 & 3.0769 \\
Machine21 & - & - & 0.7426 & - \\
Machine22 & - & - & 1.0782 & 2.6087 \\
Machine23 & - & 4.5872 & 1.7143 & 5.4545 \\
Machine24 & - & 1.5436 & - & - \\
Machine25 & - & 2.7273 & 0.4637 & - \\
\hline & & & & \\
\hline
\end{tabular}


Table 14

\begin{tabular}{lcccccccc}
\hline & Supplier1 & Supplier2 & Supplier3 & Supplier4 & Supplier5 & Supplier6 & Supplier7 & Supplier8 \\
\cline { 2 - 8 } Vehicle1 & 0.0087 & 0.0085 & 0.0084 & 0.0078 & 0.0084 & 0.0077 & 0.0077 & 0.0083 \\
Vehicle2 & 0.0072 & 0.0069 & 0.0066 & 0.0065 & 0.0068 & 0.0064 & 0.0058 & 0.0065 \\
Vehicle3 & 0.0068 & 0.0066 & 0.0061 & 0.0058 & 0.0062 & 0.0057 & 0.0056 & 0.0060 \\
Vehicle4 & 0.0064 & 0.0063 & 0.0060 & 0.0057 & 0.0060 & 0.0056 & 0.0056 & 0.0058 \\
Vehicle5 & 0.0083 & 0.0079 & 0.0074 & 0.0072 & 0.0077 & 0.0072 & 0.0066 & 0.0073 \\
\hline
\end{tabular}

\section{Appendix A}

The initial dataset of the factory is shown in Error! Reference source not found. to Error! Reference source not found. The first row in Error! Reference source not found., the candidate suppliers, indicates suppliers with the production capability of raw materials for each part. Also, the delivery lead-time of each supplier is presented in the parenthesis. The second and third row show the demand rate and due date of each part, respectively. Error! Reference source not found. presents the mean service rate of each machine for each part. Finally, the mean service rate of each vehicle for each supplier is shown in Error! Reference source not found..

Insert Table 5

Insert Table 6

Insert Table 7 